\title{
Imprinting: \\ Toward a Multilevel Theory
}

\section{CHRISTOPHER MARQUIS*}

Harvard University

ANDRÁS TILCSIK

University of Toronto

\begin{abstract}
The concept of imprinting has attracted considerable interest in numerous fields-including organizational ecology, institutional theory, network analysis, and career research-and has been applied at several levels of analysis, from the industry to the individual. This article offers a critical review of this rich yet disparate literature and guides research toward a multilevel theory of imprinting. We start with a definition that captures the general features of imprinting across levels of analysis but is precise enough to remain distinct from seemingly similar concepts, such as path dependence and cohort effects. We then provide a framework to order and unite the splintered field of imprinting research at different levels of analysis. In doing so, we identify economic, technological, institutional, and individual influences that lead to imprints at the level of (a) organizational collectives, (b) single
\end{abstract}

*Corresponding author. Email: cmarquis@hbs.edu

(C) 2013 Academy of Management

敢 $\begin{aligned} & \text { Routledge } \\ & \text { Taylor \& Francis Group }\end{aligned}$ 
organizations, (c) organizational building blocks, and (d) individuals. Building on this framework, we develop a general model that points to major avenues for future research and charts new directions toward a multilevel theory of imprinting. This theory provides a distinct lens for organizational research that takes history seriously.

\section{Introduction}

The past is never dead. It's not even past. (William Faulkner)

Nearly half a century has passed since Stinchcombe (1965) introduced the concept of imprinting to organizational research, describing how organizations take on elements of their founding environment and how these elements persist well beyond the founding phase. The concept of imprinting has attracted interest in a wide array of fields-from organizational ecology (Carroll \& Hannan, 1989; Swaminathan, 1996) and institutional theory (Johnson, 2007; Marquis \& Huang, 2010) to network analysis (McEvily, Jaffee, \& Tortoriello, 2012) and career research (Higgins, 2005)-and has become an important lens for understanding a variety of phenomena at multiple levels of analysis. Indeed, few ideas in organization theory have been applied so widely across different levels; for example, scholars have invoked the concept of imprinting in analyses of industries (e.g. Stinchcombe, 1965), intercorporate communities (e.g. Marquis, 2003), single organizations (e.g. Johnson, 2007), positions within organizations (e.g. Burton \& Beckman, 2007), and individual performance (e.g. Tilcsik, 2012). Yet, while the crosslevel application of the imprinting concept has led to a rich set of studies, it has also raised questions about the precise meaning of imprinting and the differences between imprinting processes that occur at different levels of analysis. This article, therefore, is an attempt to clarify the nature of imprinting, to integrate the disparate literatures that have engaged with the concept, and to guide research toward a multilevel theory of imprinting.

We first review the history of the imprinting concept-its origins in biological ecology and its subsequent development in organizational research-and develop a general definition and theoretical framework that integrates several cognate literatures. The widespread and varied use of the imprinting concept has led to a fragmented body of work in which imprinting often remains undefined or is defined with reference to a specific empirical phenomenon or level of analysis. This creates a risk that imprinting will become a meaningless umbrella concept. Yet imprinting has a specific meaning that goes well beyond the general notion that "history matters" and is clearly distinct from other concepts, such as path dependence or cohort effects, which describe how past conditions influence present outcomes. Thus, we seek to clarify the concept of imprinting in a way that avoids conflating distinct 
processes-and their distinct antecedents and consequences-under the umbrella of an overly elastic term. We advance a three-part definition of imprinting that emphasizes (1) brief sensitive periods of transition during which the focal entity exhibits high susceptibility to external influences; (2) a process whereby the focal entity comes to reflect elements of its environment during a sensitive period; and (3) the persistence of imprints despite subsequent environmental changes.

A unique feature of imprinting is that its relatively broad implicit definition has allowed researchers to apply the concept at several different levels of analysis, often in isolation from one another. In this essay, we provide a framework to integrate this fragmented literature by bringing together pertinent research at four different levels, including (a) organizational collectives (such as industries or communities), (b) single organizations, (c) organizational building blocks (such as jobs and occupations, subunits, and routines), and (d) individuals. At all four levels, we consider imprints left on the focal entity by economic and technological conditions, institutional factors, and particular individuals. Thus, we conceptualize the environment in which an imprint is formed as a richly textured, multifaceted space, rather than a homogeneous, one-dimensional force. Building on this perspective, we consider the mechanisms that underlie the creation of imprints by different environmental conditions at different levels and find some intriguing parallels, which facilitate conceptual cross-fertilization across distinct streams of research.

This synthesis allows us to develop new insights and open important avenues for future scholarship. First, we consider the dynamics of imprinting. Conceptualizing sensitive periods as times of transition rather than simply "early" periods, we argue that an entity can experience multiple sensitive periods over time. Thus, there is a potentially intriguing interplay between different generations of imprints that are layered upon one another, with the traces of old layers surviving despite subsequent sensitive periods. Moreover, we highlight the possibility that some imprints will fade while others persist or become even more influential over time. The tensions between imprint decay, persistence, and amplification represent a key area for future research and reflect broader tensions between inertia- and institutionalization-focused versus adaptationist perspectives.

We then turn to the indirect yet far-reaching implications of imprinting. We argue that the distinction between the historical origin and the current usefulness of an imprint is a critical conceptual tool in understanding the consequences of imprinting. This distinction allows scholars to recognize that, even though imprints tend to persist, their effects and external manifestations vary over time, reflecting an interplay of the past and the present. Furthermore, although empirical studies typically focused on imprinting due to a single environmental factor, we emphasize that imprints and the environments in 
which they are formed are multidimensional and constitute an intricate texture of different conditions. Thus, we propose to view entities as carriers of multiple intersecting imprints, a perspective that should help reveal the complex effects of imprinting processes.

Finally, building on our discussion of the dynamics and understudied implications of imprinting, we present a general theoretical model that highlights several key mechanisms, consequences, and contingencies of imprinting across levels of analysis. We conclude with a discussion of how a historical perspective can illuminate important organizational phenomena and strengthen the field of organization studies more generally.

\section{The Concept of Imprinting}

\section{Historical Overview}

The concept of imprinting emerged more than a century ago in studies of animal behavior. In 1873, British amateur biologist Douglas Spalding reported the tendency of domestic birds to follow the first-seen moving object, a behavior that was "stamped in their nature" as a result of early experience (Spalding, 1873 [1902], p. 134). The German biologist Heinroth (1911) made similar observations 20 years later, and his disciple Konrad Lorenz began to thoroughly analyze and define the phenomenon in the 1930s, calling it imprinting (Prägung). As Lorenz insisted, this phenomenon-in which early experience determines subsequent social behavior-was distinct from other learning processes. Although imprinting only occurred during a short critical period early in the life of an animal, its effects persisted even after the animal was subsequently exposed to other moving objects and separated from the first object (Lorenz, 1935, 1937). For example, even after being placed in a box to be separated from both their mother and Lorenz, goslings would reliably follow either their mother or Lorenz, depending on whom they first encountered after hatching. Lorenz's insights proved seminal among bioecologists, who have subsequently documented imprinting in a variety of animal behaviors, including sexual and food preferences, aggression, and the selection of a home area (e.g. Flanagan, 1999; Hess, 1959; Immelmann, 1975).

This line of work has emphasized two general characteristics of imprinting: "the existence of a sensitive period and the subsequent stability of the result of experience gained during that period" (Immelmann, 1975, p. 24). The first characteristic implies that imprinting occurs during a limited period of time, when an organism exhibits heightened susceptibility to environmental influences. The second characteristic implies that, despite the brevity of the sensitive period, imprinted experiences exert a persistent influence on behavior, such that "the influence of early experience resists extinction to a high degree" (Immelmann, 1975, p. 22). 


\section{Bringing Imprinting into Organizational Research}

The use of the imprinting concept in organizational studies dates to Stinchcombe's classic 1965 essay on "Social Structure and Organizations". In this essay, Stinchcombe focused on "developing a theory of the correlation of age and structure" (1965, p. 160) to understand why organizations and types of organizations founded in a common period were similar. Stinchcombe emphasized the importance of external environmental forces in shaping firms' initial structures and the persistence of these patterns over time. As he noted (1965, p. 153),

the organizational inventions that can be made at a particular time in history depend on the social technology available at that time ... both because these organizations can function effectively with those organizational forms, and because the forms tend to become institutionalized, the basic structure of the organization tends to remain relatively stable.

A prominent example in the essay involved employment patterns that exist across industries, providing evidence that industries founded in the same period still reflect the socioeconomic conditions present at their founding, such that there is "a strong correlation between the age at which industries were developed and their structure at present time" (Stinchcombe, 1965, p. 159). For instance, agriculture-at the time of Stinchcombe's writing-was typically conducted by self-employed farmers using family labor, reflecting the organizational system that was dominant when the industry began. Similarly, firms in industries that emerged following the managerial revolution at the turn of the twentieth century (Chandler, 1977) employed a higher proportion of administrative workers than firms founded in older industries.

Although Stinchcombe did not use the term "imprinting", the term soon became associated with his essay (Lounsbury \& Ventresca, 2002). For instance, in an early review of the organization-environment literature, Miles, Snow, and Pfeffer (1974) stated,

Stinchcombe has shown that organizations are "imprinted" by the conditions existing in the industry to which they belong at the time the industry is "born". He suggests that environmental conditions at any point in time not only specify the needs for particular goods and services but also determine many of the characteristics of the organizations created to provide them. (p. 259)

Since then, scores of empirical studies on Stinchcombe's imprinting hypothesis have been published.

While Sinchcombe's primary focus was at the industry level, most subsequent studies have examined how individual organizations bear a lasting imprint of founding conditions. There is also precedent for this approach in 
Stinchcombe's essay, which noted that "organizations formed at one time typically have a different social structure from those formed at another time" (1965, p. 154). For example, because most university fraternities emerged in three different waves, their present-day organizational features reflect the mark of one of these three periods. The first wave of foundings reflected the secularization of Northern liberal arts colleges in the 1840s; the second wave began in the South, amid the difficulties of post-Civil War reconciliation in the latter half of the 1860s; and the third wave came between 1900 and 1920, when marginalized populations of Black, Catholic, and Jewish students established "anti-fraternity" fraternities, emphasizing anti-discrimination goals. In subsequent periods, each of these three different types carried the legacy of their founding environment.

Although the organization has been the dominant level of analysis in much of the literature building on Stinchcombe's insights, recent years have also seen the emergence of imprinting research at the meso and micro levels of analysis. At the meso level, the concept of imprinting has proved especially valuable in understanding how and why organizational building blocks-such as jobs and occupations, capabilities, and routines-continue to reflect the circumstances of their creation (e.g. Baron \& Newman, 1990; Burton \& Beckman, 2007). At the individual level, this work has explored how early-career experiences exert a lasting influence on people's careers (e.g. Azoulay, Liu, \& Stuart, 2011; Tilcsik, 2012) and how individuals carry these imprints with them as they move across organizational boundaries (e.g. Higgins, 2005; McEvily et al., 2012).

In sum, during the five decades since Stinchcombe's essay, imprinting has become an important concept in organizational research at multiple levels of analysis, from the original focus on organizational collectives and organizations to recent efforts at the level of organizational building blocks and individuals. As we discuss below, while the resulting diversity of imprinting research might render integration difficult, it is also a source of theoretical richness, which-when systematically organized-fosters the development of new insights.

\section{Defining Imprinting}

Before describing the various streams of imprinting research in more detail, we provide a definition of imprinting as a general concept that resonates across different levels of analysis yet preserves enough specificity to provide a distinct theoretical lens. In the extant literature, imprinting is often left undefined or is defined with reference to a particular phenomenon at a single level of analysis. The absence of an explicit general definition creates a risk that the word "imprinting" will be either used as a meaninglessly broad term or as a concept that has different and fairly narrow meanings in different literatures. 
In the former case, the theoretical leverage that comes from the term's specific meaning would be lost; in the latter case, important similarities across different lines of research might be concealed, preventing the accumulation and crossfertilization of ideas across parallel literatures.

Building on the above-discussed early bioecological literature as well as Stinchcombe's seminal essay, we define imprinting as a process whereby, during a brief period of susceptibility, a focal entity develops characteristics that reflect prominent features of the environment, and these characteristics continue to persist despite significant environmental changes in subsequent periods. By this definition, imprinting has three essential features:

(1) the existence of a temporally restricted sensitive period characterized by high susceptibility to environmental influence;

(2) the powerful impact of the environment during the sensitive period such that the focal entity comes to reflect elements of the environment at that time; and

(3) the persistence of the characteristics developed during the sensitive period even in the face of subsequent environmental changes.

As we discuss below, these three general features of imprinting are common across levels of analysis even though their specific manifestations and the underlying mechanisms at the different levels are only analogous, rather than identical.

Sensitive period. The first unique feature of the imprinting argument is that an imprint is stamped onto the focal entity in limited time intervals during which the entity exhibits intensified receptivity to external influence. During these brief sensitive periods, the focal entity is significantly more malleable by environmental conditions than in normal times. Thus, the window of "imprintability" is only open during restricted periods of time, and when it is shut, the environment is less likely to have a lasting impact (Immelmann, 1975; Stinchcombe, 1965). Building on this insight, a number of studies have focused on the time of founding as the key sensitive period for organizations (e.g. Carroll \& Hannan, 2004; Johnson, 2007) and conceptualized the early-career stage as the relevant sensitive period for individuals (e.g. Higgins, 2005; McEvily et al., 2012). Both organizations and individuals are assumed to constitute more of a blank slate during such periods and to be especially receptive to external influences as they attempt to achieve fit with their environments to manage the uncertainties of newness. As Kimberly (1979, p. 438) put it, "just as for a child, the conditions under which an organization is born and the course of its development in infancy have important consequences for its later life".

Although this focus on founding and the early-career period is consistent with the bioecological view of imprinting that takes place during an early life 
stage, we suggest that sensitive periods can occur at later stages as well. In other words, while each sensitive period is relatively short, an entity might experience multiple sensitive periods over time. For example, Carroll and Hannan note that sensitive periods for imprinting occur at "key developmental stages" (2004, p. 293, emphasis added), suggesting that there might be sensitive periods other than just the founding stage. Thus, for example, going public or merging with another firm might create an occasion for organizational imprinting as the uncertainty of such transitions suddenly create new environmental demands. This notion is consistent with the observation that external environments exert a powerful influence on organizations and their building blocks during periods of organizational transition, upheaval, and instability (e.g. Greenwood \& Hinings, 1996; Tushman \& Romanelli, 1985).

Similarly, research at the individual level suggests that, during periods of role transition-including periods of organizational and professional socialization- "individuals are particularly susceptible to influence ... because of the great uncertainty regarding role requirements" (Ashforth \& Saks, 1996, p. 149). During such periods, individuals are motivated to reduce uncertainty and tend to experience cognitive unfreezing (e.g. DiRenzo, 1977; Ibarra, 1999; Van Maanen \& Schein, 1979), such that the "cognitive models that ... [they] hold can be challenged and replaced with scripts and schema that are more congruent with the new environment" (Dokko, Wilk, \& Rothbard, 2009, p. 55). As Higgins (2005, p. 338) notes,

Transitions of any kind are marked by anxiety that individuals want to reduce as they extend themselves into new roles, new identities .... Such vulnerable times amplify the potential for imprinting. This is consistent with adult development theory-being in between stages of development and experiencing tension one wants to resolve.

In sum, we suggest that-across levels of analysis-sensitive periods should be conceptualized as periods of transition. In this view, of course, the founding period remains the key sensitive period for organizations, as it marks the fundamental transition from nonexistence to existence; similarly, the beginning of an individual's career constitutes an important sensitive period because it represents a critical transition from the world of education to the world of work. Yet the possibility of multiple sensitive periods opens the way for discovering imprinting in a wider variety of instances.

Stamp of the environment. A second important element of imprinting is that core features of the environment exert a significant influence on the focal entity during sensitive periods. In the case of organizations, for example, a "mapping of an environmental condition onto the organization" takes place at this time (Carroll \& Hannan, 2004, p. 206). As we discuss in detail below, such conditions might include features of the economic, technological, or 
institutional context as well as the "logics of organizing" that founders rely on when creating the new enterprise (Baron, Burton, \& Hannan, 1999). Thus, entrepreneurs and organizational managers during the founding period play an important role in selecting the historically specific contextual features that then become a lasting part of the organization (Baron, Hannan, \& Burton, 1999; Johnson, 2007), and the selection of these features often reflects attempts at achieving isomorphism or fit with the environment to address uncertainty and legitimacy pressures (DiMaggio \& Powell, 1983; Hannan \& Freeman, 1977). As Carroll and Hannan (2004, p. 205) describe in summarizing Stinchcombe:

In attempting to accumulate financial and human capital, entrepreneurs expose their designs to intense scrutiny. Proposals get tested against taken-for-granted assumptions about structural forms and employment relations.... Consequently, the kinds of organizations that emerge reflect the social structure of the founding period.

The crux of this argument is that the organizational practices and structures that have been developed and are legitimate at a given time are relatively distinctive. Organizations are initially structured to fit the existing environment and then, because of subsequent inertia and institutionalization, continue to exhibit traces of the founding context.

An analogous argument applies to the individual level. Given the anxiety and cognitive unfreezing experienced during sensitive periods, individuals become especially open to environmental stimuli (Schein, 1971). As a result, various "means of reducing such anxiety, including looking to peers, to mentors, to leaders, can provide powerful cues as to how to behave" (Higgins, 2005, p. 338). Consequently, individuals are particularly likely to adopt new behaviors, cognitive models, and norms at these times, causing their subsequent behaviors to bear the stamp of the environment they experienced during a sensitive period (Azoulay et al., 2011; Kacperczyk, 2009; Tilcsik, 2012).

Persistence of imprints. The third element of the imprinting hypothesis is that imprints persist even if significant changes take place in the environment. At the organizational level, Stinchcome suggested a number of reasons for the persistence of structures:

(a) they may still be the most efficient form of organization for a given purpose; (b) traditionalizing forces, the vesting of interests, and the working out of ideologies may tend to preserve the structure; and (c) the organization may not be in a competitive structure in which it has to be better than alternative forms of organization in order to survive. (Stinchcombe, 1965, p. 169) 
Stinchcombe's early insight into the importance of tradition, interests, and ideologies in maintaining imprints has been elaborated by theorists focused on inertia (Hannan \& Freeman, 1977, 1984) and institutionalization (DiMaggio \& Powell, 1983). Inertia, defined as "persistent organizational resistance to changing architecture" (Hannan \& Freeman, 1984), is a powerful mechanism that maintains the initial structural features of an organization and implies that "changing a core feature exposes an organization to great risk of mortality" (Carroll \& Hannan, 2004, p. 64). Persistence also results from institutionalization (DiMaggio \& Powell, 1983; Scott, 2008), that is, the emergence of stable, orderly social arrangements that are "chronically reproduced ... [because of] relatively self-activating social processes” (Jepperson, 1991, p. 145). According to the institutionalization perspective, organizations create explicit "goals and rules, coordination mechanisms, and communication channels" (Scott, 2008, p. 124), which subsequently persist because they become taken for granted and "infuse[d] with value beyond the technical requirements of the task at hand" (Selznick, 1957, pp. 16-17).

Similarly, a defining feature of individual-level imprinting is the long-term persistence of imprints beyond the sensitive period. Studies in a variety of populations, including managers, lawyers, and scientists, suggest that even when individuals leave behind the early, apprenticeship stage of their careers, they continue to carry with them the beliefs, behaviors, and orientations adopted during this formative period (Azoulay et al., 2011; Higgins, 2005; McEvily et al., 2012). And, because people tend to experience less uncertainty when not going through a role transition, they tend to be less receptive to learning and environmental influences outside sensitive periods. As a result, imprints linger on.

In sum, to rectify the absence of an explicit general definition of imprinting, our definition cuts across different levels of analysis, identifying three core dimensions that are common to imprinting whether it occurs at the macro, meso, or micro level. As we will elaborate below, the precise nature of these dimensions varies across levels; for example, sensitive periods and the mechanisms that contribute to imprint persistence take a very different form in the case of organizations or industries than in the case of individuals. Yet the basic elements of our definition are conceptually analogous across levels of analysis, creating novel opportunities to recognize both the fundamental similarities and the unique aspects of imprinting phenomena at different levels.

\section{What Imprinting is Not}

To clarify the meaning of imprinting, it is necessary to distinguish it from other concepts that describe how the past shapes the present. Path dependence (Arthur, 1989; David, 1994; Mahoney, 2000) and cohort effects (Elder, 1974; 
Ryder, 1965) are two of the most commonly invoked concepts capturing such influences.

Path dependence. The concept of path dependence describes the "surprising manner in which historical small events can become magnified by positive feedback", causing "the economy, under conditions of increasing returns, [to] dynamically lock itself in as a result of chance decisions that is neither guaranteed to be efficient, nor easily altered, nor predictable in advance" (Powell, 1991, p. 193). Economic historians have provided numerous examples of how a technology or organizational practice "locks in" and-as a result of accumulated advantage-continues to persist even if it is not the most efficient choice in a subsequent period. The VCR video format, for example, gained an early advantage over the technologically superior Betamax, leading to its eventual proliferation and success (Arthur, 1990); likewise, the current dominance of the QWERTY keyboard format can be traced back to its early adoption (David, 1985).

Imprinting as we define it is clearly distinct from path dependence in a number of ways. Unlike path dependence, imprinting involves (1) prominent environmental conditions rather than historical accidents, (2) short sensitive periods rather than long-term event chains, and (3) the stability of stampedin features rather than the increasing dominance of a pattern.

First, the notion of imprinting emphasizes prominent environmental conditions, while "proponents of a path dependence perspective often celebrate historical accidents" (Garud \& Karnøe, 2001, p. 2), emphasizing "singular historical events" (Sydow, Schreyögg, \& Koch, 2009, p. 690), "including happenings dominated by chance elements rather than systematic forces" (David, 1985, p. 332). According to Vergne and Durand, a defining feature of imprinting is the "very strong" influence of environmental conditions during the sensitive period, while a path dependence view focuses on the causal role of "unpredictable, non-purposive, and somewhat random events" and attributes only "very weak" influence to the environmental conditions emphasized in imprinting research (2010, pp. 741-742). Thus, path dependence is often seen as resulting from a single event that occurs "because of the unpredictable actions of individuals... or through the chance conjuncture" of other events (Johnson, 2008, p. 30); imprinting, by contrast, reflects prominent elements of the environment during a sensitive period.

Second, while a defining feature of imprinting is the brevity of the relevant sensitive period, path dependence scholars often focus on sequences of events over a long period, highlighting "a steady accumulation of small differences" (Garud \& Karnøe, 2001, p. 2). As Mahoney noted, path dependence refers "specifically [to] those historical sequences in which contingent events set into motion institutional patterns or event chains that have deterministic properties" (2000, p. 507; emphases added). In other words, path dependence is a 
result of the full "set of outcomes and opportunities that arose in a history" (Page, 2006, p. 97), reflecting the entire pathway by which an actor arrived at a certain point (e.g. Breen \& Jonsson, 2000). Thus, while "the replicated pattern in the imprinting approach is ready-made" during a short sensitive period, path dependence is a "product of later processes, which are initially unknown" (Sydow et al., 2009, p. 696).

Third, the mechanisms that underlie the two concepts also differ. The imprinting perspective emphasizes the persistence of environmental conditions stamped in during a brief sensitive period. Theories of path dependence, by contrast, "explain the unfolding process of path formation, not only the reproduction of ... properties" that had been formed during a sensitive period (Sydow et al., 2009, p. 696). That is, while path dependence captures "how a specific pattern of social practices ... gains more and more predominance" over time (Sydow et al., 2009, p. 704), imprinting is concerned with how patterns formed during a brief sensitive period remain stable. Thus, when theorizing what happens following the initial period, path dependence scholars often focus on the dynamics of increasing returns and chaotic processes (e.g. Arthur, 1989; Baum \& Silverman, 2001; Page, 2006) to understand how paths unfold (Vergne \& Durand, 2010); imprinting research, on the other hand, emphasizes the persistence of stamped-in contextual features.

Cohort effects. It is also instructive to distinguish imprinting from cohort effects. A cohort is an aggregate of actors, such as individuals or organizations, that share a common set of experiences because they were born or founded at the same time or because they entered the same state (e.g. began their career or education in the case of individuals) within the same time interval (Aldrich \& Ruef, 2006; Joshi, Dencker, Franz, \& Martocchio, 2010). Cohort effects, in turn, refer to a high degree of similarity in characteristics and outcomes within cohorts. As Rosow notes, cohort effects describe "the typical response patterns of members of various cohorts to the same thing. Those in one generation react the same way, but differently from members of another" (1978, p. 72). For example, individuals joining a firm at the same time often enter similar employment contracts and are exposed to similar experiences at each stage of their organizational tenure, leading to significant intra-cohort homogeneity in attitudes and work outcomes (Joshi et al., 2010).

Cohort effects differ from imprinting in several ways. Most broadly, whereas cohort effects represent an outcome (that results from a variety of processes, but not necessarily imprinting), imprinting is a process (which leads to a variety of outcomes, but not necessarily cohort effects). Clearly, not all cohort effects are due to imprinting. Cohort effects emerge because actors have similar continued experiences throughout their life course (e.g. Elder, 1974; Ryder, 1965); imprinting of susceptibility - and these periods matter in spite of subsequent experiences. Likewise, not all imprinting processes generate cohort 
effects. While a cohort effect implies a high degree of intra-cohort homogeneity (Rosow, 1978), imprinting might not lead to such homogeneity because members of a given cohort may be imprinted with different experiences. For example, individuals in the same cohort in the same organization or occupational field might be assigned to different mentors, peers, or tasks early in their careers, leading to significantly different experiences during this sensitive period (e.g. Azoulay et al., 2011; Kacperczyk, 2009; McEvily et al., 2012). Similarly, the founders of organizations might bring different organizational models or blueprints to their new enterprise, potentially creating different imprints even within a group of firms that are founded at the same time (see Baron, Hannan, \& Burton, 1999). In such cases, imprinting occurs without causing cohort effects.

\section{Imprinting Research at Multiple Levels: Integrating a Fragmented Literature}

Streams of imprinting research at different levels of analysis have often been developed in isolation from one another, leading to a balkanization of the literature and making it difficult to integrate insights across levels. As Johnson noted, empirical studies on imprinting often "differ so dramatically from one another in theoretical approach, method, level of ... analysis, and time span under investigation as to render comparisons and conclusions difficult" (2008, p. 16). To provide some integrative order to this splintered field, we review the diverse streams of literature that have drawn on the imprinting concept and, in Table 1, provide a basic framework to order this large body of work. The four main columns of this table represent four major types of entities that bear imprints. These include, moving from the macro to micro level, (a) organizational collectives, (b) organizations, (c) organizational building blocks, and (d) individuals. At all these levels, the rows represent three different sources of imprints: (a) economic and technological conditions; (b) institutional factors (including regulative, normative, and cultural-cognitive factors; Scott, 2008); and (c) particular individuals. In the intersecting cells in the table, we provide a summary and examples of the mechanisms by which imprinting occurs. Below we discuss each of these cells in the same order as they are numbered in Table 1.

\section{Imprinting at the Level of Organizational Collectives}

Numerous studies have shown that organizational collectives bear imprints of their founding environment, including the stamp of economic, technological, and institutional conditions and the mark of founding individuals. Such collectives can be defined on the basis of organizational and market characteristics (e.g. industries), geography (e.g. organizational populations embedded in particular nation-states and geographic communities) or shared organizational 


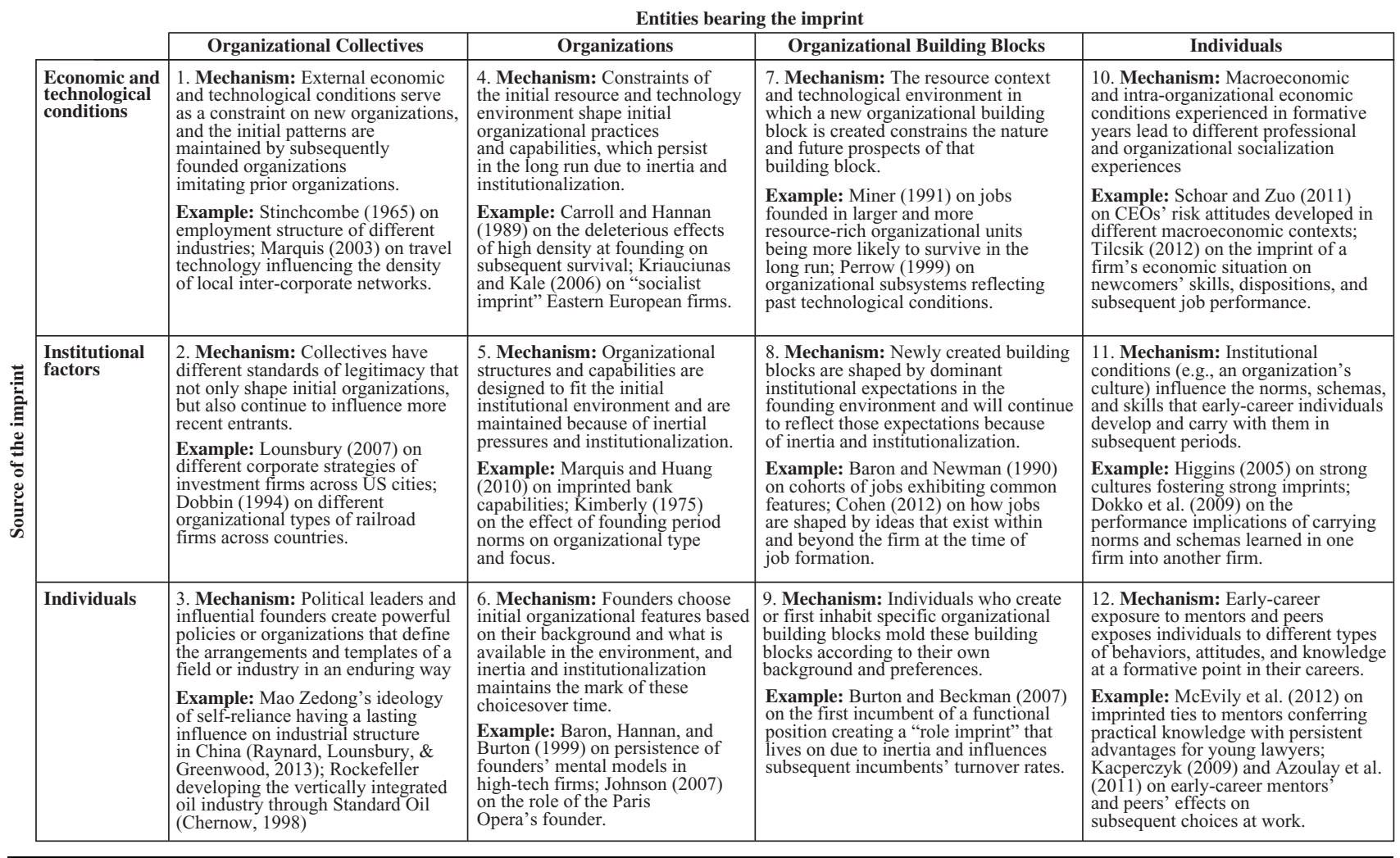


form. In general, imprinting occurs in these collectives because the founding environmental conditions serve as constraints for early entrants, and the patterns that are established at that time are then perpetuated by subsequent organizations' emulation of the collective's older members.

Imprints of economic and technological conditions on organizational collectives. As noted above, Stinchcombe's (1965) primary example of imprinting is that industries are imprinted with employment patterns that exist at the time of industry founding such that the industry-level imprints are perpetuated despite substantial environmental changes in the later periods. This occurs because the available economic and technological conditions at the time of founding influence the initial form of employment in an industry. For instance, organizations in the agricultural sector (i.e. farms) were established in a period of limited transportation and markets so they were typically home-based and run with family employment. A crucial nuance of such industry-level imprinting is that it is maintained by newer organizations following the imprinted industry patterns. For instance, farms founded at the time of Stinchcombe's writing still tended to be family-run because this was the legitimate organizational form established at industry founding and was subsequently imitated by newer organizations as well. Moreover, the remainder of the agricultural supply chain was set up in ways that were consistent with production by home-based, family-operated organizations, which further contributed to the persistence of the imprint.

Regarding the imprints borne by geographic collectives, Marquis (2003) showed a similar pattern, whereby limitations in transportation technology during the establishment of community-based intercorporate networks led early corporations to establish geographically bound networks. And, despite subsequent changes in technology and organizational types, new firms founded in cities, where such a pattern had been imprinted, were still likely to form locally focused networks, modeling themselves on the existing firms. Thus, in the case of both industries and geography-based collectives, economic and technological conditions at founding shape initial organizational structures and activities, but it is through subsequent institutional processes-new organizations modeling themselves on the existing organizations-that imprints are maintained at the level of collectives.

One important line of work related to the imprinting of organizational collectives has examined the emergence of new organizational forms (Clemens, 2002). As this research demonstrates, economic and technological conditions shape the kinds of organizational forms that arise in a given period, and the resulting new forms might persist, continuing to bear a mark of the time when they first emerged. For example, Chandler's (1977) argument about managerial coordination and bureaucracy suggests that new organizational forms arose as a result of changing technological conditions, such as the development 
of the railway and the telegraph, and then persisted subsequently. Similarly, Haveman and Rao (1997) showed that a new type of thrift savings organization was created in California between the 1860s and 1920s to meet the needs of new populations due to technology-driven migration, and more recent studies have examined how modern information technologies made new organizational arrangements possible (O’Mahony \& Ferraro, 2007; O'Mahony \& Lakhani, 2011). While not always tied to the notion of imprinting explicitly, this diverse research suggests that-to the extent that new forms live on in subsequent periods - the focal organizational population will continue to reflect the economic and technological conditions under which its organizational forms first arose.

Imprints of institutional conditions on organizational collectives. Several studies have focused on how initial institutional conditions affect organizational collectives. An obvious boundary for organizational collectives is defined by national borders, and Kogut (1993) proposed a process of "country imprinting" that affects how multinational companies change and adapt to new countries as they expand beyond their home country. This assertion resonates with a broader literature, which-while not always explicitly tied to imprinting - has shown that national cultures and traditions have an enduring influence on constituent actors. Inglehart and Baker (2000), for instance, studied values across 65 countries and found that distinctive cultural traditions persist at the national level even in the face of modernizing influences. Thus, the "broad cultural heritage of a society_Protestant, Roman Catholic, Orthodox, Confucian, or Communist-leaves an imprint on values that endures despite modernization" (Inglehart \& Baker, 2000, p. 19). This national cultural imprint, Inglehart and Baker argue, is maintained by educational institutions and the mass media.

While not explicitly an imprinting study because it does not directly address how the imprints were originally formed, Dobbin's (1994) analysis of railroad policy in France, the USA, and Great Britain does provide a helpful example of how imprints might be maintained at the country level. Dobbin shows that the different approaches for developing the railroad industry taken by France (where planning and financing by the central state played the key role), the USA (where protections of a free market to ensure competition loomed large), and Britain (where small entrepreneurial firms were favored and protected) were a result of organizational and policy decisions that reflected deeper cultural traditions and corresponding political structures. As a result, these broad country-specific patterns remained largely intact despite subsequent upheaval in the environment. For example, even when the Great Depression called into question fundamental ideas about the economy, these countries reversed their traditional policies only temporarily and then reliably returned to their normal paradigm by the end of the 1930s (Dobbin, 1993). 
A number of studies have found that imprints are also maintained at the level of the geographic community (Marquis \& Battilana, 2009). Lounsbury (2007) showed how the strategies of mutual funds differed between Boston and New York depending on the historical cultural imprint in those cities. In Boston, where a trustee logic had been established in the investment industry early on, mutual funds focused on conservative, long-term investing. In New York, where a more aggressive, financially driven logic prevailed, firms focused on growth money management strategies. Marquis, Davis, and Glynn (2013) showed that founding conditions in cities, whereby corporate elites established dense networks at the turn of the twentieth century, persistently affect the type and magnitude of corporate support for local nonprofit organizations. In cities with long-standing traditions of elite cohesion, elitefocused nonprofits in the arts, culture, and private education continue to grow at a disproportionately high rate even in the present day. Echoing a similar theme, Greve and Rao (2012) found that early founding of nonprofit organizations created an institutional legacy of civic commitment in Norwegian communities, which then led these communities to establish other nonprofits even a century later.

Institutional conditions also shape the emergence of new organizational forms associated with industries and social movements. For example, Schneiberg's (2002) study of the rise of the mutual form of fire insurance in resistance to corporate consolidation "highlights how new organizational forms are forged within the crucible of broader societal conflicts over economic development" (Lounsbury \& Ventresca, 2002, p. 20). Research has documented that social movements tap the broader cultural context to create new and enduring organizational forms (e.g. Carroll \& Swaminathan, 2000; Rao, Monin, \& Durand, 2003). Similarly, studies by Haveman and Rao (1997) and Haveman, Rao, and Paruchuri (2007) have shown "that the Progressive movement left visible and potent imprints on political culture, in the form of laws, news media, and role-model organizations" (Haveman et al., 2007, p. 119), which contributed to the rise of thrifts emphasizing progressive values. Thus, given that emerging organizational forms come to reflect the prevailing institutions, organizational collectives likely carry a legacy of the institutional order under which their characteristic organizational forms emerged.

Imprints of individuals on organizational collectives. While few empirical studies have investigated how individuals or groups of individuals might leave a lasting mark on an industry or field, the existing research suggests two types of leaders that might have such an imprinting effect: political leaders and influential entrepreneurs.

Regarding political leaders' imprints, two cases that help illustrate this effect are Mao Zedong's imprint on the current industry structures in China and 
Louis XIV's enduring mark on organizational forms in French art and science. Following the Chinese communist revolution in 1949, China took a unique path toward industrialization, which continues to affect the current industry arrangements. Raynard et al. (2013) argue that Mao played a particularly important role in this imprinting process. As Raynard et al. (2013, p. 15) note, the "guiding state logic under Mao was centered on notions of 'selfreliance' and 'self-sufficiency'-with 'a preference for human power, manual labor, mass mobilization over technology, intellect, and efficiency"' (Fan, 1995, p. 423). This approach contributed to what Mao called his "third-line" strategy whereby strategic industries were dispersed across the country. The resulting patterns influence industry location and structure to this day. The Chinese airline industry, for example, is concentrated around the relatively remote city of Xi'an in central China, a location that Mao originally chose for this strategic industry because it was farthest from both the coast and the Soviet Union (Fallows, 2012). Another example of an enduring imprint of a political leader on an organizational collective is Louis XIV, who

spent a great deal of energy and money on the creation of ... [a] system of [royal] academies because it occupied a key position in his efforts to centralize the administration of France around his person and to raise France above all other countries in cultural production. (Johnson, 2007, p. 108)

The resulting imprint on French arts and sciences, and the associated organizational forms, is visible even centuries later (Johnson, 2008).

Anecdotal evidence suggests that influential entrepreneurs may also have such an effect through the creation of novel products or business models. Hsu and Kenney (2005), for example, describe how the early leaders of the venture capital pioneer American Research \& Development Corporation (ARD) left an imprint on the practice of modern venture capital. ARD's founders, associated with institutions such as Harvard Business School, MIT, and the Boston Federal Reserve, pioneered practices that later became staples of the venture capital industry, like professional evaluation and after-investment support. Similarly, historical accounts document the fundamental role of several early industrialists in other areas. Rockefeller's personal vision, for instance, shaped the vertically integrated oil industry in the long run (Chernow, 1998), and Carnegie played a similar role in the steel industry (Nasaw, 2006). An interesting aspect of these examples is the critical role of powerful organizations that allow individuals to leave a lasting mark on a broad field or industry. For example, while Rockefeller himself had the idea of vertically integrating the oil industry, it is only through the power of Standard Oil that he was able to accomplish this. Thus, a mechanism worthy of future investigation is the process whereby particular organizations become vehicles that facilitate the imprinting of organizational collectives by individuals. 


\section{Imprinting at the Organizational Level}

The imprinted influence of founding conditions on organizations represents one of the most active research areas in the literature. This diverse body of work has examined an eclectic set of imprinting processes and outcomes, from ecologists' focus on organizational survival to studies of imprinting in post-communist economies to research on founder imprints. Below, we review the distinct mechanisms in each of these areas.

Imprints of economic and technological conditions on organizations. Organizational ecologists have focused on how population density at organizational founding affects future survival. Developing the concept of "density delay", Carroll and Hannan (1989) showed that, across five different organizational populations, the level of organizational density at the point of a firm's founding had a persistent positive relationship to subsequent organizational mortality. Two explanations have been proposed for this finding. First, being founded at a time of high density leads to a liability of resource scarcity for new entrants, which hampers subsequent organization building. Second, because niches are tightly packed in times of high density, entrants in those periods are forced to the periphery and must exploit marginal resources. The relationship between high density at founding and mortality has been replicated in several studies (Carroll \& Hannan, 2004). For example, in a study of Sweden's information technology industry, Zaring and Eriksson (2009) have shown that density at founding persistently led to an increased failure rate. Dobrev and Gotsopoulos (2010) further elaborated the mechanisms behind density delay, showing that in the early years of an industry, when the new types of organizations lack legitimacy, the imprinted density effect is especially strong, presumably because new entrants in an emerging industry are exposed to a "legitimacy vacuum", and this exposure is imprinted on their structures and practices in a largely irreversible way. Contrary to these findings, however, a study of mortality rates of U.S. breweries and Argentine newspapers suggested a "trial-by-fire" model, whereby-beyond a certain organizational age-firms founded in periods of high density had lower mortality rates than those established in less-adverse environments (Swaminathan, 1996). This argument suggests that being founded in difficult times might enhance resilience later.

Other researchers have focused more explicitly on the different capabilities and routines that are imprinted by initial economic and technological conditions. Zyglidopoulos (1999), for example, theorized that organizations would persistently follow the technological paradigm dominant at founding. Tucker, Singh, and Meinhard (1990) studied voluntary social service organizations in Toronto, finding that features of the founding environment, such as periods of higher resource availability due to regulatory changes, and higher 
organizational density, exerted persistent effects on subsequent rates of change across an array of organizational processes.

A fruitful context for imprinting research has been the transition from socialist to market economies throughout the world. These studies show that the broader economic system in which an organization is founded leaves a strong imprint, making post-transition adaptation difficult for organizations founded in a socialist regime. For example, research in Eastern Europe suggests that firm-specific capabilities and knowledge resources developed to meet the needs of one economic system are persistent and prove to be era-specific such that these "socialist imprints" adversely affect knowledge routines as well as competitive aspirations after the economic transition (Kogut \& Zander, 2000; Kriauciunas \& Kale, 2006; Shinkle \& Kriauciunas, 2012). In China, studies have found that older firms, which were shaped more profoundly by the Communist bureaucracy, have deeply entrenched structures and vested interests and are less likely to adopt new governance practices (Marquis \& Qian, 2013; Peng, 2004). In all these cases, the "pressures that reflect the logic of capitalism are ... exerted on organizations that were created under Communism" (Tilcsik, 2010, p. 1476), and this fundamental contradiction helps reveal the powerful force of organizational imprints.

Imprints of institutional conditions on organizations. Some of the earliest empirical studies following Stinchcombe's essay examined the founding institutional conditions that shape organizations. As Carroll and Hannan (2004, pp. 446-447) explain, organizations tend to "incorporate prevailing social and political arrangements - not to mention fads and fashions in management-into organizational designs and to retain these distinctive features long after founding”. For example, Kimberly (1975) showed that whether sheltered workshops, a type of organization that provided work-oriented rehabilitation for the handicapped, were production-focused or rehabilitation-oriented depended on the prevailing social philosophy at founding. Meyer and Brown (1977) examined how the civil service movement and legislation influenced the bureaucratization of finance agencies, with older agencies bearing an imprint of more extensive formalization that was characteristic of earlier times. Focusing on the business sector, Boeker studied semiconductor firms and showed that the type of financing opportunities available during the founding period exerted a persistent influence on organizations' strategy and target market (Boeker, 1988, 1989b).

More recently, scholars have extended this literature by adding more nuance to both the process and the consequences of institutional imprints. Johnson (2007) showed that institutional conditions-existing organizational templates and the powerful authority of the French state-shaped and constrained the strategic choices of the Paris Opera's founder, with persistent 
consequences for the organization. Capitalizing on historical variation across U.S. states, Marquis and Huang (2010) argued that institutional conditions present in a focal firm's state at the time of founding powerfully influence organizational capabilities and that these persistent capabilities have different external manifestations in subsequent historical eras. Firms that were founded in states where regulatory and political cultural conditions promoted intra-organizational coordination were more likely to subsequently acquire other organizations, an activity that capitalizes on the previously developed coordination experience.

Imprints of individuals on organizations. Some of the most compelling evidence about imprinting concerns the lasting effects of individual founders on organizations. One line of research has employed a qualitative approach to understand how such imprints emerge and persist. For example, in an early longitudinal study of the birth and development of a medical school, Kimberly (1979) showed that the founder's personality and initial decisions had a lasting effect on a variety of subsequent organizational strategies and actions. In a study of a French computer firm, Kimberly and Bouchikhi (1995, p. 16) described the founder imprinting process, noting that "the definition of core values early on, along with choice of domain, insistence by the CEO in maintaining a majority ownership position, and the nature of the early hires has set this organization on a particular trajectory", casting it in a mold persistently. More recently, in her case study of the Paris Opera, Johnson (2007, p. 97) highlighted the importance of "entrepreneurs in selecting and incorporating historically specific elements that may remain for decades or even centuries as fundamental features of the organization in question". Thus, while the broader context is critically important, organizations take on elements of their founding environment through individual founders: it is "entrepreneurs who stamp new organizations with the distinctive signs of their founding times" (Johnson, 2007, p. 122). Thus, different founders' decisions to incorporate certain environmental elements, but not others, can lead to variation in imprints even across organizations that are established at the same time.

Other researchers have demonstrated the influence of founder imprints quantitatively. For instance, in their studies of the Silicon Valley high-tech start-ups, Baron, Burton, and Hannan measured founders' mental models and initial decisions and then tracked how these founding conditions influenced subsequent organizational trajectories. This research suggests that the organizational patterns set by a founder have persistent effects on a wide array of outcomes even after the founder leaves the firm. The employment models of founders, for example, mattered more for organizational employment patterns than did those of the current CEO (Hannan, Burton, \& Baron, 1996). A founder's employment model, in particular, exerted an enduring influence on managerial intensity; over time, administrative roles and 
personnel proliferated to a greater extent in firms that were founded by entrepreneurs who preferred a bureaucratic employment model (Baron, Hannan, \& Burton, 1999). This result is consistent with the idea that "the founder's blueprint likely 'locks in' the adoption of particular structures" and, perhaps more important, that "it also 'locks in' certain premises that guide decision making" later on (Baron, Hannan, \& Burton, 1999, p. 531).

Phillips (2005), for example, concluded that the blueprints that founders bring with them to a new law firm continue to affect the firm's internal gender hierarchy for an extended period of time. In particular, founders who come from parent firms where female leadership was historically the norm are more likely to found progeny firms that subsequently promote women into partnership positions. This finding is particularly interesting because it not only shows that founders leave a lasting imprint on organizations but also suggests that the founders themselves bear an imprint due to their prior experiences. It is this individuallevel imprint that leads a founder to institute routines similar to those in the parent firm, thereby imprinting the newly founded organization with a blueprint to which he or she had been previously exposed. Burton, Sørensen, and Beckman (2002) suggest a similar process in a study on the organizational origins of startup founders, arguing that founders who come from entrepreneurially prominent firms are more likely to pursue an innovation-based strategy than those whose prior employer is less visible in the entrepreneurial community. Both these studies draw attention to the possibility of imprint transfer, whereby established organizations leave powerful imprints on individuals, who in turn transfer these imprints to their own ventures as founders.

In the above-mentioned studies on semiconductor firms, Boeker also uncovered several types of founder imprints. Investigating the impact of founding choices on organizational structure, he found that the previous functional experience of the founder was positively associated with the importance of that function in the organization in subsequent periods (Boeker, 1989b). And, when founders adopted a single or dominant initial strategy for a new firm, that strategy likely persisted in the long run, especially when the distribution of power and influence within the firm reinforced the initial strategic direction (Boeker, 1989a). Documenting a similar process whereby the initial choices of managers imprint future organizational activities, a four-decade study has shown that venture capital firms' very first decision to invest early in a new high-technology industry leaves a strong imprint on their subsequent investment decisions, particularly among firms that had greater investing experience at the time of the first decision (Dimov, de Holan, \& Milanovy, 2012).

\section{Imprinting at the Level of Organizational Building Blocks}

Organizational building blocks are elements from which organizations are constructed, such as units and departments, routines and capabilities, and jobs, 
occupations, and professions. These "building blocks for organizations... [are] littered around the societal landscape", and entrepreneurs and managers "assemble them into a structure" (Meyer \& Rowan, 1977, p. 345). Thus far, relative to the focus on organizations, imprinting research has accorded only modest empirical attention to organizational building blocks. At the same time, while the imprinting of building blocks is not directly examined in many studies, it is frequently theorized as a mechanism in organization-level research. As noted above, for example, Marquis and Huang (2010) developed theory about how institutional conditions at founding affected intra-organizational capabilities - important organizational building blocks - and found evidence consistent with this theory by observing banks' propensities to engage in acquisitions in subsequent historical eras. Others have focused on other types of building blocks, such as routines and knowledge sets within firms, when theorizing the impact of socialist imprints on firms' adaptation to market-based economies (e.g. Kriauciunas \& Kale, 2006; Shinkle \& Kriauciunas, 2012). In all these cases, organizational building blocks played a central role, but it was ultimately at the organizational level that the imprints of interest manifested themselves.

A handful of studies have examined building blocks more directly, focusing on them as the primary outcome of imprinting. Much research in this area has focused on jobs, occupations, and positions. As Cohen (2012, p. 1) noted, "Jobs are fundamental organizational building blocks. They are the bundles of tasks performed by employees under administrative job titles .... The forms of jobs contained in an organization may determine the very form of that organization." This stream of research has pointed to the role of economic and technological conditions, institutional factors, and individuals in the imprinting of organizational building blocks.

Imprints of economic and technological conditions on organizational building blocks. There has been relatively little direct work on economic or technological imprinting at the level of organizational building blocks, but some studies do provide suggestive evidence on this topic. For instance, invoking the concept of imprinting to understand the "social ecology of jobs", Miner (1991) has argued that the economic context of job formation within an organization affects the prospects of the job in subsequent periods; in particular, jobs founded in larger and more resource-rich organizational units might be more likely to survive in the long run than those formed in smaller and relatively resource-poor units. Thus, economic conditions at the creation of a particular building block can influence whether it survives within an organization. Other research, although not directly tied to imprinting, has provided examples of how technological conditions imprint organizational building blocks. As Perrow $(1984,1999)$ emphasized, for instance, organizational subsystems reflect the technology available at the time of their creation and rarely 
change fundamentally because most changes involve adding technological patches to older subsystems, rather than replacing them entirely. As a result, organizational building blocks continue to carry the legacy of their genesis.

Imprints of institutional conditions on organizational building blocks. Research on the imprinting of jobs and occupations has begun to uncover the imprinted influence of institutional factors on organizational building blocks. In a key study on this issue, Baron and Newman (1990) suggest that jobs continue to reflect institutional arrangements that were appropriate at the time of job formation. Thus, "notions of imprinting ... might fruitfully be extended to the study of work roles: cohorts of jobs founded during the same period might be expected to evince common features, such as shared selection and promotion criteria and similar degrees of ascription" (Baron \& Newman, 1990, p. 172). In the California state civil service, for example, the devaluation of female work was greater in older jobs-those founded at a time when gender stereotypes played a greater role in perceptions of job worth. By contrast, jobs founded or revised more recently exhibited a smaller pay penalty for women, reflecting growing institutional pressures for pay equity in more recent times. A key implication is that jobs, occupations, and professions are susceptible to imprinting and are likely to carry a legacy of the institutional environment in which they were formed.

Adding some nuance to the study of institutional factors in job imprinting, Cohen (2012) studied the intra-organizational process of job creation qualitatively. Examining how ideas for work arrangements were developed following the installation of a new DNA sequencer in nine different organizations, she identified multiple sources of ideas relevant to the design of new jobs. Cohen's findings suggest that the creation of jobs within firms reflects the interaction of the external institutional environment and intra-organizational actors, and jobs come to be shaped by ideas that exist within and beyond the organization at the time of job formation. To the extent that the resulting job designs persist, jobs will continue to reflect both the broader macroinstitutional environment and the local micro-institutional context in which they were initially formed.

Imprints of individuals on organizational building blocks. Burton and Beckman (2007), too, stress the importance of local firm histories but focus more directly on how particular individuals imprint functional position within an organization. They argue that the first occupant of a position defines the position based on his or her skills, background, and experiences, thus leaving a potent and persistent legacy that will continue to constrain subsequent position holders. Demonstrating the power of "position imprints", Burton and Beckman show that the characteristics of first incumbents have a strong and long-standing effect on successors' turnover rates. If the first 
incumbent has an atypical functional experience (e.g. a finance executive position is first held by someone with an engineering background), subsequent position holders tend to have high turnover rates. In contrast, successors who match the position imprint have relatively low turnover rates, even when examining the third or fourth successor, and even if they are atypical with respect to normative expectations in the external environment. Thus, the normative benefits from matching a firm-specific position imprint seem to overshadow the costs of violating broader normative expectations. Local imprints appear to overwhelm dominant external norms in the present.

\section{Imprinting at the Individual Level}

Imprints of economic conditions on individuals. In recent years, a growing number of scholars have invoked the concept of imprinting to describe how early experiences in a career or organizational tenure exert a lasting effect on individuals' behaviors in the long run. One line of research in this area has begun to uncover how economic conditions affect the types of skills and dispositions that individuals develop during sensitive career stages. This work suggests, for example, that managers who started their careers during a recession tend to make more conservative decisions as CEOs than those who experienced a more favorable initial environment. These imprinted differences are observable in a variety of financial decisions, including those concerning leverage, diversification, cost effectiveness, and capital expenditures (Schoar \& Zuo, 2011). One likely mechanism is that,

young managers who start [their career] in a recession might acquire a different set of skills and adopt a different mindset if they learn their trade in a time when resources are scarce rather than when they are easily available. (Schoar \& Zuo, 2011, p. 4)

Similarly, macroeconomic conditions experienced early in life have been linked to individual investors' willingness to take financial risk even several decades later (Malmendier \& Nagel, 2011).

Other scholars have focused on economic conditions inside organizations, rather than the broader macroenvironment. Among mutual fund managers, for example, the amount of financial risk present within a firm at an individual's early-career stage shapes long-term entrepreneurial choices with regard to external versus internal venture formation (Kacperczyk, 2009). Likewise, Tilcsik (2012) suggests that the level of intra-organizational resource abundance at the time of organizational entry has long-standing consequences, noting that while some newcomers undergo socialization in a time of organizational prosperity, others arrive in a period of relative scarcity. The resulting experiences leave radically different imprints on individuals, with important implications for subsequent work performance. For example, Tilcsik argues 
that the more similar the initially experienced level of resource abundance to the current level of resource abundance, the higher the focal individual's job performance.

Imprints of institutional conditions on individuals. A second line of individual-level research investigated the imprinted effects of institutional factors, especially the norms and cognitive schemas associated with different organizational cultures. Focusing on the healthcare and biotech industries, Higgins (2005) has argued that an organization's culture-along with its structure and strategy-dramatically shape not only the level and type of human and social capital that early-career managers develop, but also their "takenfor-granted assumptions, beliefs, and values" (Higgins, 2005, p. 10). According to Higgins, these dimensions jointly constitute a lasting career imprint, and this imprint will be especially deep and persistent if it was formed in a strong organizational culture. Similarly, Dokko et al. (2009) emphasize the role of organizational culture in cultivating career imprints. They argue that, through socialization into an organization, individuals develop potentially persistent schemas, scripts, and normative assumptions about how work is to be performed. As a result, when people move to a new organization, they carry with them not only skills and knowledge, but also a cultural imprint of norms, routines, and schemas that they had learned from prior work experience (see also Phillips, 2005).

Consistent with this idea, both Higgins (2005) and Dokko et al. (2009) have documented the powerful performance and career implications of individuallevel imprints that are carried across organizational boundaries. Studying the performance patterns of employees in a major U.S. insurance firm, Dokko and her colleagues argue that-when the current organizational context is substantially different from a prior, formative environment-imprinted cognitive and behavioral patterns "act as baggage, weighing down [individuals'] responsiveness or ability to reflect in the new situation" (Dokko et al., 2009, p. 54). Such imprints also loom large in Higgins' account of how and why a single firm could become a successful breeding ground of a generation of industry leaders in the biotech sector (see also Burton et al., 2002). According to Higgins, because of the imprints left on its employees' careers, the Illinoisbased healthcare company Baxter International generated a disproportionate number of leaders in the biotech industry-people who began their careers in the 1970s at Baxter, where they developed line management skills and an orientation toward bottom-line results, which in turn allowed them to succeed in the entrepreneurial environment of the emergent biotech industry in the early 1980s. In contrast, early-career experiences during the 1970s at Abbott Laboratories-another Illinois-based healthcare company-fostered a functional career imprint oriented toward sales skills and top-line results. This imprint was much less closely matched with the demands of the 1980s 
biotech sector. Clearly, individual-level imprints-which reflect, in part, core aspects of the organizational culture during sensitive career periods-may have significant consequences well beyond shaping individual cognition and behavior.

Imprints of individuals on other individuals. Finally, a third stream of individual-level research has focused on the socially transmitted influence of role models and peers to whom the focal individual is exposed during a sensitive period. In a five-decade study of the Nashville legal industry, for example, McEvily et al. (2012) argue that the early years of lawyers' careers constitute a highly formative learning period during which exposure to mentors affects the amount of practical knowledge young lawyers acquire, which contributes to the growth of the firms in which they subsequently serve as partners. Bringing the notion of individual-level imprinting to the study of network dynamics, McEvily and colleagues develop the concept of "imprinted ties", that is, individuals' ties to experienced mentors during the early, formative stages of their careers. The results not only show that the growth of law firms is influenced by the extent to which their partners' imprinted ties were bridging ties between otherwise disconnected network segments, but also demonstrate that this imprinting effect is more robust than the conventionally documented effect of rapidly decaying opportunity structures. By infusing the imprinting concept into network research, this study highlights the neglected possibility that bridging ties produce benefits over an extended time period and contributes a novel insight to an established paradigm.

While McEvily and his colleagues focused on firm performance as the outcome of individual-level imprinting, other scholars have documented how early-career mentors and peers affect individuals' career- and workrelated choices in the long term. For example, the orientation of early-career mentors toward commercial science affects scientists' patenting behavior well into their careers (Azoulay et al., 2011); the characteristics of earlycareer coworkers continue to shape mutual fund managers' entrepreneurial decisions for years to come (Kacperczyk, 2009); and the level of same-race representation at the time of organizational entry influences individuals' turnover rates even years after entry (Sørensen, 2004). An important theoretical and methodological contribution in this domain is the conceptualization of social influence that occurs under conditions of partially deliberate matching between actors. As Azoulay et al. (2011) argue, when individuals match with associates (such as peers or mentors) on a small set of dimensions, they are also inadvertently exposed to unanticipated social influences. That is, when an individual chooses to pair with another, she might not consider the entire set of preferences and attitudes possessed by her counterpart, thereby opening herself to "unanticipated social influences that arise from the attributes of [her] associates that never entered [the] calculus when [they] chose 
to interact" (Azoulay et al., 2011, p. 3). Young scientists, for example, match to mentors at the postdoctoral stage of their careers on the basis of two main factors, geography and research focus. And, even though they do not match on orientation toward commercial science, they subsequently adopt their advisers' preferences in that domain-and carry that imprint in the long run. The general lesson is that attributes that are incidental when forming a relationship, but consequential once it is formed, help researchers estimate the causal effect of interpersonal influence-a key task for scholars interested in the imprints that individuals leave on one another.

\section{Expanding the Scope of Imprinting Research}

As the previous section demonstrates, the past five decades have produced a rich and varied literature on imprinting. Nevertheless, much work remains to be done to realize the full potential of the concept, to extend its reach into new areas, and to eliminate critical gaps in our understanding. Thus, we now turn to the implications and some extensions of our perspective on imprinting. Doing so allows us to identify important unexplored areas and chart directions for future research. We focus on two broad areas of fundamental importance. First, we consider the dynamics of imprinting, particularly the possibility of multiple sensitive periods during a life course and the tensions between imprint decay and persistence over time. This discussion expands the scope of imprinting research well beyond the founding period and the early-career stage. Second, we discuss some unexplored yet powerful implications of imprinting, focusing on the differences between the origin and current utility of imprinted characteristics as well as the interplay of different imprints. Although these implications are subtle, complex, and often difficult to discern, their influence is potentially strong and far-reaching. Overall, these two areas-the dynamics and far-reaching ramifications of imprinting-suggest several critical avenues for further research.

\section{Imprinting Dynamics}

Our definition of imprinting opens new ways for understanding how imprinting unfolds over time. First, two elements of our definition focused on the stamp of the environment placed upon the focal entity during a sensitive period, noting that more than one sensitive period might exist during a life course. As we discuss below, the possibility of multiple sensitive periods has major implications for the scope and focus of imprinting research. Second, the last element of our definition emphasized the persistence of characteristics developed during sensitive periods. This emphasis on persistence rather than permanence or irreversibility implies that some imprints might fade over time; thus, understanding the survival and potential decay of imprints is a key task for future research. In what follows, we first discuss the implications 
of multiple sensitive periods and then the tensions between imprint persistence and decay.

Multiple sensitive periods. A basic assumption behind most imprinting research at the organizational level is that "the creation of a new organization is one of the most salient moments of its life cycle" (Pennings, 1980, p. 254). While this statement stresses the importance of the founding period, it also implies that organizational birth is one, but not necessarily the only, salient moment in the life cycle. As our definition of imprinting suggests, transitions-for instance, the process of becoming a public company, merging with another firm, changing industries, or replacing the senior management team-might also constitute sensitive periods later in the life of an organization. Similarly, while the beginning of a career is a sensitive period of great importance for individuals, subsequent transitions between career stages, roles, or organizations are also potentially "vulnerable times [that] amplify the potential for imprinting" (Higgins, 2005, p. 338).

The possibility of multiple sensitive periods greatly increases the scope and applicability of the imprinting perspective. It implies that major organizational and career transitions are important not only because of their direct effects but also because it is during these periods that the environment molds the focal entity with long-standing consequences. Yet, although such transitions have generated intense interest in a range of fields, their potential role in shaping organizational and individual behaviors in the long run has gone largely unnoticed. For example, much influential work has examined organizations' structural, ownership, and leadership transitions (Beatty \& Zajac, 1994; Harrison, Torres, \& Kukalis, 1988; Walsh, 1988) as well as the transition of individuals across organizations and roles (Groysberg, Lee, \& Nanda, 2008; Ibarra, 1999; Rosenkopf \& Almeida, 2003), but little attention has been given to the imprints that are formed during these transitions. We suggest that understanding the environment during such salient periods could explain important long-term variation in organizational and individual behaviors.

This perspective also suggests that we might fruitfully view organizations as layers of imprints, reflecting not the cumulative total of the historical conditions they experienced, nor just the stamp of the founding environment, but rather the imprints of the environments in which they operated during a small number of sensitive periods. This view implies a superposition of imprints-a process whereby layers of history are deposited in organizations at a few specific points in time. In this sense, we might study organizations much like archeologists who examine the temporal succession of strata at an excavation site, identifying the critical contexts in which different layers were formed. This view echoes the idea of "sedimentation", the process whereby new organizational features and practices are layered upon old ones, rather than replacing them entirely (Cooper, Hinings, Greenwood, \& 
Brown, 1996). As the traces of old layers are not swept away when new layers form, complex sets of "layered features, practices, and ideas" build up in organizations over time (Cooper, Rose, Greenwood, \& Hinings, 2000, p. 118), and those layers that are deposited during sensitive periods are especially resistant to erosion. A similar approach might also apply to the individual level, where several sensitive periods can potentially contribute to the formation of a career imprint (Higgins, 2005). At all levels of the analysis, untangling the influence of multiple sensitive periods represents a promising future direction into largely uncharted territory.

One task for such research will be to examine the extent and nature of managerial agency in organizational imprinting. While imprinting is sometimes seen as an ecological force devoid of agency, the existence of several sensitive periods implies some room for managerial action beyond the founding period. It suggests that not only founders but also subsequent generations of managers might play an active role in selecting environmentally available elements that will persist in the organization (cf. Johnson, 2007), although such selection will take place only at a few points in time and within a specific historical context. Thus, while there appears to be room for agency beyond the initial period, it is agency that is both socially embedded (Battilana, 2006; Pache \& Santos, 2010) and temporally constrained.

Imprint persistence and decay. In a more general sense, the issue of agency in imprinting also raises questions about the extent to which organization can deviate from imprinted patterns over time. These questions reflect a basic tension between the persistence and decay of imprints. While considerable research has shown imprinted characteristics to be quite persistent, there is also evidence that imprints may fade under certain conditions. One possibility is that, as the competitive context changes over time, the initially learned responses or knowledge sets are no longer advantageous in the new environment, which might lead to more active organizational attempts to change. Thus, questions about imprint decay reflect the general debate between inertia- (Hannan \& Freeman, 1989) and institutionalization-focused (DiMaggio \& Powell, 1983) versus adaptationist strategic choice perspectives (Child, 1972; Pfeffer \& Salancik, 1978).

Numerous studies have argued that firms attempt to modify imprinted features. Kriauciunas and Kale (2006), for example, showed that following the transition to a market economy in Eastern Europe, firms that sought new knowledge from market economies were able to modify their socialist imprint. Marquis and Huang (2010) suggested that, in addition to possessing imprinted coordination capabilities, banks learned new coordination practices that affected their expansion strategies as they encountered new environments. And Boeker (1989a) found that firms might veer from their imprinted strategies when organizational performance declines. Similarly, in response to 
market feedback, a spin-off venture might attempt to free itself of its parent firm's imprint by unlearning inappropriate routines and developing new capabilities (Ferriani, Garnsey, \& Lorenzoni, 2012). Thus, as Bamford, Dean, and McDougall noted in a study on the gradually diminishing effect of initial conditions on bank performance, the persistence-but not permanence-of imprints reflects "a moderate view that organizations are both inertial and adaptive" (2000, p. 261). In some situations, as the environment changes, significant countervailing pressures may push organizations to diverge from the imprints they carry; at the same time, inertia and institutionalization tend to render such divergence partial and gradual, helping to maintain the enduring, although not perpetual, legacy of sensitive periods.

One source of variation in the extent to which organizational imprints persist or decay is a set of intra-organizational features akin to what Stinchcombe (1965, p. 169) called internal "traditionalizing forces". Studying firm age and CEO tenure, for example, Boeker (1989b) showed that when traditionalizing forces were weaker (e.g. among younger firms and those with newer CEOs), divergence from an imprinted strategy was more likely. Conversely, Eisenhardt and Schoonhoven (1990, p. 526) found that for firms founded with larger management teams, which they propose to be more advantageous in their setting, "the effects of initial conditions among this cohort of ventures ... were amplified, not diminished with time". Similarly, Sullivan, Tang, and Marquis (2013) showed that U.S. venture capital firms that were founded into small-world networks were imprinted with a learning capability such that they subsequently outperformed their otherwise similar peers, and that this performance benefit increased over time. Thus, depending on certain internal characteristics, the effects of some imprints might be magnified over time. Overall, how internal processes affect the persistence, decay, and perhaps even amplification of an imprint is an intriguing area for future research.

At the individual level, similar tensions exist between imprint persistence and decay and, more generally, between perspectives that emphasize imprinting and those that stress continuous learning throughout the career (see McEvily et al., 2012). Yet little research has examined the dynamics of imprint decay at the individual level, and the evidence thus far has been inconclusive (Tilcsik, 2012). One empirical difficulty is that the existing studies have not typically observed individuals repeatedly over a long period of time after the supposed sensitive period. Collecting such data is a critical task because the conditions that make imprints more or less persistent deserve serious empirical attention.

\section{Unexplored Implications of Imprinting}

The indirect and relatively unexplored ramifications of imprinting represent a second major area ripe for further investigation. To date, much research has 
focused on the persistence and direct effects of imprinted features, typically establishing an association between early contextual indicators and current characteristics. Less attention has been given to the indirect implications of imprinting, its second-order ramifications farther down the causal chain, and the interplay of different imprints. Mapping these subtle and complex implications is crucial to a more complete understanding of imprinting. In this section, we discuss two sources of analytic leverage for identifying such implications: (1) distinguishing between the origin and the current utility of imprinted characteristics, and (2) conceptualizing actors as carriers of intersecting imprints.

Distinguishing historical origin and contemporary utility. While most prior research has focused on the persistence of the same set of characteristics or activities over time, recent studies have begun to explore some of the more complex and surprising manifestations of imprints by building on a distinction between the historical origin and contemporary use of imprinted features. A key example of this work is research on "exaptation" (Gould, 1980, 1991; Marquis \& Huang, 2010), a process whereby a function or capability that was developed as an adaptive response to initial conditions becomes useful for a different purpose following an environmental change. This idea was originally developed in biology to explain functions that took on new and unexpected uses in subsequent periods. The feathers of birds, for example, may have been initially developed for heat regulation; over time, however, feathers have became useable for a different function-flight. The key point is that feathers might not have originally evolved to allow for flying, but they might have been exapted for this new function (Gould \& Vrba, 1982). An example of exaptation from research on technology evolution is that the compact disc, originally used as a durable and effective way to play back recorded material, later became highly useful as a data storage medium for computers (Dew, Sarasvathy, \& Venkataraman, 2004). In their study of bank acquisitions, Marquis and Huang (2010) directly connect the idea of exaptation to the broader ramifications of imprinting. They show that institutional and technological conditions at founding led to imprinted coordination capabilities, which were originally developed to manage geographically dispersed bank branches; subsequently, however, these capabilities could be leveraged for a different purpose-managing the acquisition and integration of other organizations - which allowed banks to compete more effectively in a national acquisitions market. This research helps "uncover a rarely attended imprinting phenomenon: deeply-established and often unobservable organizational capabilities developed as adaptive responses to founding conditions may result in different external manifestations as environmental conditions change" (Marquis \& Huang, 2010, p. 1442). Thus, while external conditions may imprint actors in ways that are predictable based on the nature of the 
environment during a sensitive period, the manifestations and effects of imprints become more complex and less predictable as the environment changes over time.

These insights are important partly because they challenge the prevailing notion that organizations experience a "liability of aging" or obsolescence (Baum \& Shipilov, 2006). According to the liability of aging hypothesis,

older organizations are ... at greater risk of disbanding than younger ones... [because] both individual organizations and organizational forms often 'lock into' strategies and structures used during their early years. As the social environment of these organizations changes, they may become increasingly mismatched with contemporary conditions. (Ruef, 2002, pp. 201-202)

By assuming that older organizations are necessarily more obsolete, however, this argument conflates historical origin and contemporary utility, two distinct dimensions that should be assessed separately in order to understand how the legacy of the past influences the present.

Imprinting research at the individual level has arrived at a similar insight, suggesting that the implications of a given imprint depend on the nature of the environment in which the focal actor subsequently operates, and that an imprint that emerged in one context might provide both advantages and disadvantages when carried into a different context. As Higgins noted,

it is important to understand that a career imprint can be perfectly suited to one type of job or industry, while clashing irrecoverably with another. Organizational career imprints can bring with them both opportunities and constraints, depending upon the organizational context into which they are imported. (2005, p. 4)

And, although not examined explicitly in prior research, exaptation might play an important role at the individual level as well. Higgins (2005), for example, described how early employment experiences at the healthcare firm Baxter imprinted young line managers with a sophisticated ability to liaise with governmental actors and international constituents. An exaptation perspective suggests that such formative experiences might prove useful for another purpose in a very different position as well-not just for line managers negotiating with overseas regulators but also, for example, in diplomatic or political careers. Thus, a career imprint that was adaptive in one context may detract from performance or may become useful for a different purpose in a subsequent environment.

These perspectives suggest that a nuanced theory of imprinting should not only consider the persistence of past characteristics but also illuminate how and why their subsequent manifestations may be more or less functional for different purposes in different environments. As Gould noted, 
no conceptual tool can be more important than the clear separation of historical origin and current utility. The false conceptual passage from present function to initial construction ranks with the post hoc fallacy and the confusion of correlation with cause as primary errors of reasoning about temporal sequences. (1991, p. 45)

Understanding how imprints linger and have powerful yet complex, unanticipated, and easily obscured manifestations is one antidote to the functionalist logic that is pervasive in much of organizational theory. Moreover, the distinction between origin and current utility highlights how the manifestation of an imprint might vary over time, depending on the nature of subsequent environments. Thus, while imprints are persistent, their effects are not constant. Accordingly, a major avenue for future research is to explore the timevarying, contingent influence of imprints, reflecting an interplay between the imprinted past and the present context.

Intersecting imprints. Organizations and individuals operate in a "richly textured n-dimensional space” (Lounsbury \& Ventresca, 2002, p. 3). They are embedded in an economic and technological environment as well as an institutional context of regulative, normative, and cultural-cognitive forces (Scott, 2008). Simultaneously, organizations are subject to the influence of their founders and managers, and individuals are susceptible to the social influence of peers, mentors, and other individuals. As our review indicates, all these elements of the environment might play a powerful role, potentially leaving multiple imprints on an entity even during a single sensitive period. Thus, as Johnson noted, "imprinting processes emerge from intersections of multiple conditions" (2008, p. 33). Moreover, if entities carry layers of imprints acquired in multiple sensitive periods, different generations of imprinted characteristics will exist within an entity.

To date, however, the influence of multiple coexisting imprints has received little empirical attention. Thus, one major shortcoming of imprinting research is the lack of understanding of how imprints due to different environmental forces and different sensitive periods interact with one another. While some research has examined how different founding conditions-such as regulatory policy, technology, and political culture-reinforced or weakened each other's effects in particular empirical cases (Marquis \& Huang, 2010), we are far from even a nascent theory that describes intersecting imprints and how they modify one another's influence more generally.

One concept that might enrich the development of such theory is the notion of secondhand imprinting (Tilcsik, 2012). Secondhand imprinting refers to the social transmission of imprints, a process whereby an actor takes on aspects of an imprint borne by another actor. At the individual level, for example, secondhand imprinting might occur if newcomers to an 
organization learn norms and routines by imitating the behaviors of their veteran colleagues that reflect, in part, these experienced coworkers' career imprints. In this case, a newcomer's learning is indirectly influenced by others' formative experiences. A similar process might occur when a new firm emulates the structures and practices of older organizations (DiMaggio \& Powell, 1983) - including the imprinted patterns present in those structures and practices. In such cases, the focal firm not only takes on elements of its own broader economic and institutional environment (as in the case of firsthand or direct imprinting) but also incorporates imprinted elements from earlier eras that survived in the architecture and routines of older firms (secondhand imprinting). Sometimes both these processes will foster the adoption of similar environmental elements, reinforcing each other; in other cases, however, the two processes may lead the new firm to be imprinted by a more diverse set of elements, some reflecting the contemporary founding context and others reflecting a different set of patterns carried forward from an earlier period by the mimicked organizations. The coexistence and interplay of these different and potentially inconsistent imprints within an actor warrant further research. In general, conceptualizing actors as carriers of intersecting imprints - which might arise because of (a) different environmental forces, (b) different sensitive periods, or (c) secondhand imprinting-should be a promising path to move forward at all levels of analysis.

\section{Implications of a Multilevel Theory of Imprinting}

The goal of this essay was to take stock of imprinting research and to reorient it in promising new directions. To do so, we first provided an explicit general definition of imprinting and developed a framework to unite this fragmented body of research (Table 1). This framework not only points to fundamental gaps and research opportunities in the literature, particularly with regard to the understudied dynamics and unexplored implications of imprinting, but also provides the basis for a general model of imprinting across levels of analysis, shown in Figure 1.

The left side of Figure 1 depicts a sensitive period for the focal entity, which might be an organizational collective, single organization, organizational building block, or individual. During this period, an imprint is established as the focal entity comes to reflect elements of its environment. A critical aspect of this model is the multidimensionality of the environment and the resulting imprint. The environment is not a homogeneous setting but a varied, $n$-dimensional space in which a set of economic, technological, and institutional conditions, as well as the influence of particular individuals, coexist and jointly constitute the stamp of the period. Further contributing to this imprint are the features of other entities that the focal entity emulates; the adoption of 


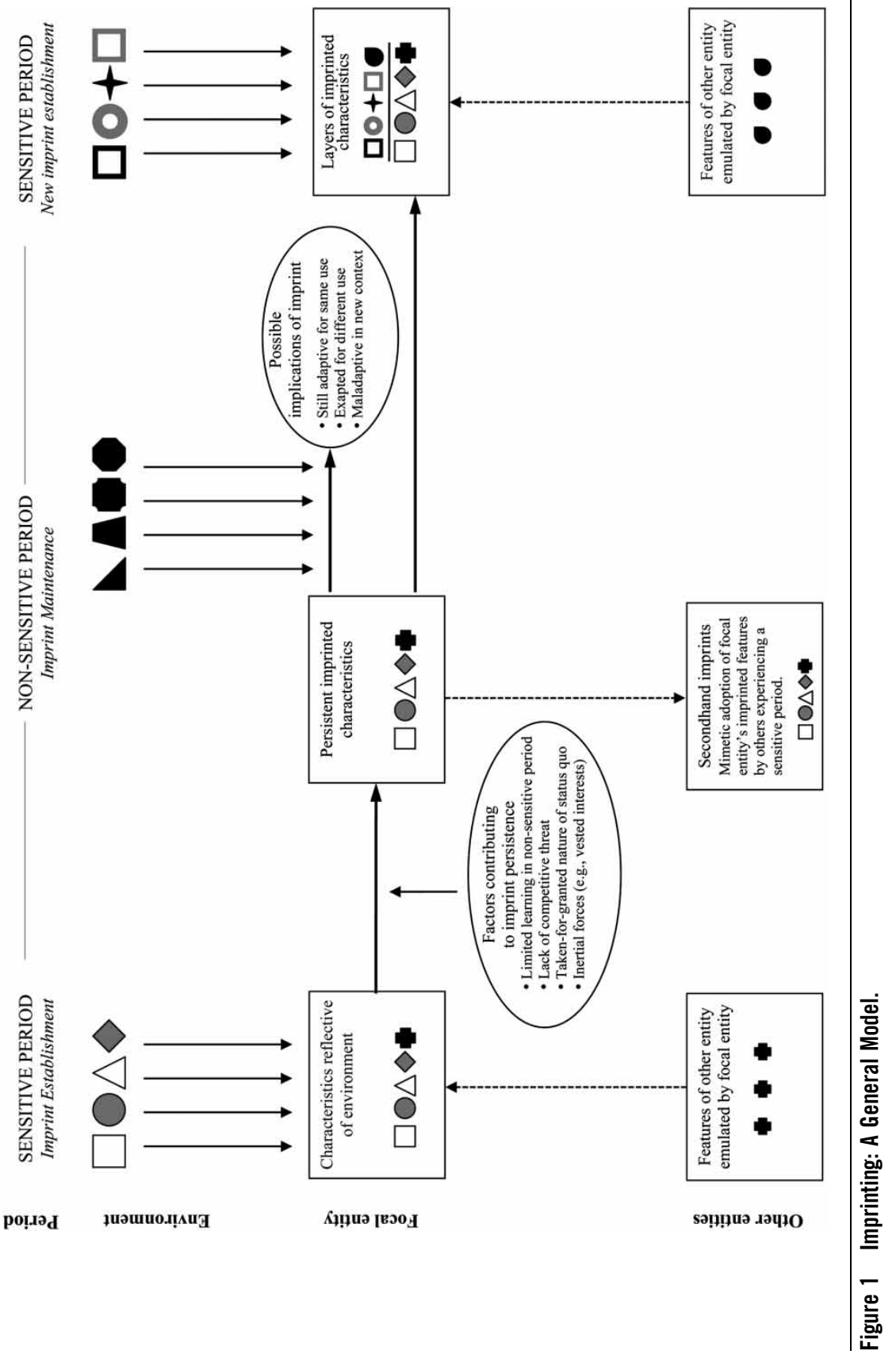


these features further shapes the mold in which the focal entity is cast. Consequently, an intricately textured, multidimensional imprint is formed.

The middle part of Figure 1 depicts imprint maintenance-a long, nonsensitive period during which imprints persist. As we emphasized, however, persistence does not imply permanence, and extant research has already suggested some factors that contribute to imprint decay over time. Moreover, the middle section of the figure highlights the possibility of secondhand imprinting, whereby other entities that are undergoing a sensitive period adopt some of focal entity's imprinted features such that these features become a part of their imprint as well. This section of the figure also depicts some of the consequences of imprinting as the environment changes during the nonsensitive period. Reflecting our distinction between historical origin and contemporary utility, this part of the model suggests that-depending on the interplay between imprinted features and the current context-imprints might remain adaptive, become maladaptive, or become exapted for different purposes.

Finally, the right side of the figure depicts a second sensitive period. During this time, a new imprint is established, reflecting environmental conditions as well as features of other, emulated entities. This new imprint is layered upon the existing imprint, rather than replacing it entirely. As we emphasized, this process might take place more than once during a life course, and the implications of viewing entities as layers of imprints represent an important topic for future scholarship. Indeed, in general, Figure 1 is more of a road sign for further research than a detailed map of documented imprinting processes. Much careful study of the dynamics and implications of imprinting remains to be done, and the relationships and mechanisms depicted in Figure 1 offer a host of promising research opportunities at all levels of analysis.

\section{Taking History Seriously: Imprinting and the Future of Organizational Studies}

By conceptualizing imprinting in a theoretically grounded way, our goal has been to unpack how and why the history of organizations and the individuals within them matters for understanding the present. Over the past two decades, numerous scholars have criticized "the largely ahistorical character that organisation studies has gained during its development as a separate discipline in the second half of the twentieth century" (Üsdiken \& Kieser, 2004, p. 321; see also, for example, Jones \& Khanna, 2006; Kieser, 1994; Zald, 1990). Although many important studies with a historical perspective have been published (e.g. Calori, Lubatkin, Very, \& Veiga, 1997; Dobbin, 1994; Greenwood, Díaz, Li, \& Lorente, 2010; Guillén, 1994; Leblebici, Salancik, Copay, \& King, 1991), standard approaches to studying contemporary outcomes and processes rarely include an examination of how past conditions shape present phenomena. As our review shows, however, past conditions and events often continue to matter even after taking into account present conditions. Thus, history cannot be 
simply controlled away with variables measured in the present: its influence lingers, affecting a wide range of important phenomena. To paraphrase Gieryn (2000), nothing of interest to organizational scholars exists without a history; everything and everyone we study carry with them elements of the past.

But simply recognizing that history matters is of little help unless we understand how it matters (Jones \& Khanna, 2006; North, 1990). Thus, we need specific, middle-range theories that are "applicable to a restricted set of [historical] sequences, but with a greater theoretical and empirical value" than the vague notion that history matters (Vergne \& Durand, 2010, p. 737). The concept of imprinting offers such a theory, providing one important lens through which to understand how the past influences the present. A key strength of this lens is that, rather than viewing history "as a linear process ... a story of progress", it helps unpack history "as a process involving disruption amidst continuity" (Cooper et al., 2000, p. 118). Its focus on brief sensitive periods of transition and long periods of continuity, in particular, clarifies how specific phases of the past (rather than the vague totality of historical conditions) matter.

We argue that such a perspective can illuminate issues central to organizational and management theory, even though many of these issues are not typically considered historical in nature. To illustrate the utility of taking history more seriously, we discuss below some examples of how a historical perspective could provide a deeper insight into four important topics in organizational scholarship: institutions, networks, careers and inequality, and leadership. This discussion is by no means exhaustive; rather, it provides but a few brief examples to illustrate how organizational research might benefit from a stronger focus on historical influences.

Institutions. Although historical approaches play an important role in institutional scholarship (Djelic \& Ainamo, 2005; Dobbin, 1994; Lounsbury, 2002), even closer attention to the legacy of past conditions could further enrich institutional theorizing. One intriguing possibility would be to connect the notion of intersecting imprints to the burgeoning literature on institutional complexity-the situation when organizations "confront incompatible prescriptions from multiple institutional logics" (Greenwood, Raynard, Kodeih, Micelotta, \& Lounsbury, 2011, p. 318). Institutional complexity may arise within organizations that experienced multiple sensitive periods, each characterized by a different dominant logic. In such cases, the focal organization is imprinted with the dominant institutional logic at founding and then, in a subsequent sensitive period, is imprinted with a different prevailing logic. Thus, institutional complexity emerges because the logic that was encoded in the organization's structures, culture, and routines at founding may be incompatible with the logic that is dominant during the second sensitive 
period. As a result, different elements of the organization come to reflect incompatible institutional prescriptions, potentially creating persistent intraorganizational tensions. The precise nature of this process and organizations' response to it is an important topic that deserves serious attention and could provide new insights into the emergence of institutional complexity.

In addition to resulting from conflicting imprints due to multiple sensitive periods, institutional complexity can also lead to multidimensional, intersecting imprints even within a single sensitive period. When an organization experiences a sensitive period in an institutionally complex environment, the resulting imprint will likely consist of potentially incompatible elements. Why and how such imprints, characterized by internal contradiction, persist or perish is an intriguing question. Their persistence, in particular, would imply that institutional complexity experienced in a sensitive period affects an organization in the long run. Past complexity, in other words, might linger inside organizations. Exploring such persistence could provide new insight into the "institutionalization within organizations of practices associated with different logics" (Greenwood et al., 2011, p. 354) and further illuminate how "over the longer term, institutional complexity unfolds" (Greenwood et al., 2011, p. 319).

Networks. While the empirical literature on social networks has traditionally focused on the contemporaneous implications of networks (e.g. Burt, 1992; Lin, 2010; Mizruchi \& Stearns, 2001; Portes, 1998; Xiao \& Tsui, 2007), recent research has begun to explore the lingering influence of past network structures and positions (Ahuja, Soda, \& Zaheer, 2012; Marquis, 2003; McEvily et al., 2012; Soda, Usai, \& Zaheer, 2004; Sullivan et al., 2013). This nascent research reflects the notion that "a past network, with its accumulated relational experience, becomes a kind of 'network memory' that cannot be ignored as it may project a structural overhang over the present, much like a shadow of the past" (Soda et al., 2004, p. 893). Despite this recent development, much remains to be learned about network imprinting and, more generally, the lingering effects of network history.

In particular, taking history seriously in network research means focusing future research attention on two fundamentally distinct aspects of network history. First, is the importance of past ties, whereby a connection in the past might exert an enduring influence on the focal actor or entity in the present, even after the connection ceases to exist. In a pioneering study of this process, McEvily et al. (2012) showed that young lawyers' network ties to experienced mentors led to persistent career advantages because these early ties provided valuable knowledge that was difficult to acquire subsequently. To the extent that networks constitute an important way through which new knowledge, practices, and routines are acquired, studying past ties and structural positions is essential to fully understand how actors' 
capabilities and expertise have come about through social networks (Soda et al., 2004). A second network process that warrants a historical approach is network persistence, whereby the structure of a network bears the imprint of conditions that prevailed during a relevant sensitive period, such that "network interactions are reproduced over time and across a number of actors" (Ahuja et al., 2012, p. 439). As Marquis (2003) showed, one reason for network persistence is that once a network is established, new network entrants are likely to imitate the existing structural patterns of prominent network members. Such persistence, in turn, creates enduring variation in the nature of networks, potentially affecting knowledge flows and actors' access to information in the long run. These examples suggest that past networks can indeed cast an influential shadow over the present, so a sole focus on current network structure would lead to an incomplete understanding of how social structure shapes behavior.

Careers and inequality. A rich literature has explored the role that organizations play in shaping careers and in producing and maintaining inequality in the workplace (e.g. Baron \& Bielby, 1980; Beckman \& Phillips, 2005; Castilla, 2008; Kalev, Dobbin, \& Kelly, 2006). While some scholars in this tradition have examined the lasting effects of early-career events (e.g. Briscoe \& Kellogg, 2011; DiPrete \& Eirich, 2006; Rosenbaum, 1979), we are still far from a detailed understanding of how past conditions shape the distribution of opportunities and rewards within organizations. An imprinting perspective offers several ways to move forward. It suggests, in particular, that historical factors cause organizations to vary significantly in their hierarchies, positions, and routines that limit or exacerbate inequality (see Phillips, 2005) and in the extent to which they create opportunities for some groups (e.g. white men) at the expense of other groups (e.g. women, minorities). Uncovering the precise nature of such variation could add significant explanatory power to organizational theories of inequality. Moreover, an imprinting lens offers a unique opportunity for career researchers to understand the interplay of past and present explanatory factors rather than studying them in isolation. As we emphasized, the career implications of individual-level imprints are likely to depend on the organizational context in which the focal individual operates in the present; thus, a given imprint might produce advantage for an individual in one environment and disadvantage in another. To date, prior research that examined the lingering effects of the past on careers and inequality has given relatively little attention to how the implications of past conditions vary depending on the current conditions (e.g. DiPrete \& Eirich, 2006; Rosenbaum, 1979). An imprinting lens highlights the contingent influence of the past and takes career history seriously without neglecting the powerful influence of the current environment. 
Leadership. The behavior and performance of top managers has attracted considerable interest from organizational scholars (e.g. Glynn \& Raffaelli, 2010; Hambrick, 1989; Mayo \& Nohria, 2005), and the existing research has revealed the influence of numerous contemporaneous factors on top managers' decisions and the resulting organizational outcomes (e.g. Chatterjee \& Hambrick, 2007; Dahl, Dezső, \& Ross, 2012; Gulati \& Westphal, 1999; Westphal \& Zajac, 2001). Complementing this focus, a historical perspective would draw attention to explanatory factors beyond the conventional scope of this literature. Studies on imprinting, for example, suggest that economic conditions and organizational experiences at critical life and career stages exert an enduring influence on how leaders manage organizations and make decisions (e.g. Higgins, 2005; Phillips, 2005; Schoar \& Zuo, 2011). Moreover, as we noted, the implications of such imprints are likely to be contingent on the nature of present conditions. This suggests that exploring the interplay between leaders' critical experiences in the past and the context in which they operate in the present could provide new explanations for the success and failure of both leaders and their organizations. We know, for example, that CEOs who began their careers in a recession tend to make more conservative financial decisions than those who started in a boom period (Schoar \& Zuo, 2011). How do these imprinted attitudes affect a CEO's performance under different macroeconomic conditions in the present? More generally, how do different imprints create a match or mismatch between leaders and their current material or institutional environment, and with what consequences for organizations? For example, is a mismatch between a leader's imprinted experiences and the current environment necessarily detrimental for an organization, or could it be an enabling condition for norm-breaking innovation (see Palmer \& Barber, 2001) and institutional entrepreneurship (Battilana, Leca, \& Boxenbaum, 2009)? Answering these questions should provide fresh insights into the determinants and consequences of organizational leaders' behaviors.

\section{Conclusion}

We encourage future research on imprinting as a powerful way to understand how and why history matters. In many streams of social science, the question of how the past casts a shadow over the present is a critical issue. From economists who study path dependence to sociologists with a historical perspective, researchers have documented the importance of historical forces in numerous domains. Yet, in much organizational and management research, the specific mechanisms whereby the past impinges on the present remain relatively unexplored. We have argued that imprinting is both more pervasive (existing at multiple levels of analysis and at multiple sensitive periods) and more farreaching in its implications (exerting a profound influence on performance, survival, and a variety of other outcomes) than single empirical studies were 
able to document. Thus, the concept of imprinting not only helps researchers pinpoint when history matters but also serves as a powerful tool to systematically identify significant but often subtle contextual influences across levels and over time. It is a perspective that allows organizational scholars to bring history-the history of broader social systems as well as organizational and individual histories-back to center stage.

\section{Acknowledgements}

We thank Julie Battilana, Royston Greenwood, Victoria Johnson, Mike Lounsbury, Bill McEvily, George Shinkle, Sameer Srivastava, and Art Stinchcombe for helpful comments on earlier versions of this paper.

\section{References}

Ahuja, G., Soda, G., \& Zaheer, A. (2012). The genesis and dynamics of organizational networks. Organization Science, 23(2), 434-448.

Aldrich, H., \& Ruef, M. (2006). Organizations evolving (2nd ed.). London: Sage.

Arthur, W.B. (1989). Competing technologies, increasing returns, and lock-in by historical events. The Economic Journal, 99(394), 116-131.

Arthur, W.B. (1990). Positive feedbacks in the economy. Scientific American, 262(February), $92-99$.

Ashforth, B.K., \& Saks, A.M. (1996). Socialization tactics: Longitudinal effects on newcomer adjustment. Academy of Management Journal, 39(1), 149-178.

Azoulay, P., Liu, C.C., \& Stuart, T.E. (2011). Social influence given (partially) deliberate matching: Career imprints in the creation of academic entrepreneurs (Working Paper). Cambridge: Harvard University.

Bamford, C.E., Dean, T.J., \& McDougall, P.P. (2000). An examination of the impact of initial founding conditions and decisions upon the performance of new bank start-ups. Journal of Business Venturing, 15(3), 253-277.

Baron, J.N., \& Bielby, W. (1980). Bringing the firms back in: Stratification, segmentation, and the organization of work. American Sociological Review, 45, 737-765.

Baron, J.N., Burton, M.D., \& Hannan, M.T. (1999). Engineering bureaucracy: The genesis of formal policies, positions, and structures in high-technology firms. Journal of Law, Economics, and Organization, 15(1), 1-41.

Baron, J.N., Hannan, M.T., \& Burton, M.D. (1999). Building the iron cage: Determinants of managerial intensity in the early years of organizations. American Sociological Review, 64, 527-547.

Baron, J.N., \& Newman, A.E. (1990). For what it's worth: Organizations, occupations, and the value of work done by women and nonwhites. American Sociological Review, 55, 155-175.

Battilana, J. (2006). Agency and institutions: The enabling role of individuals' social position. Organization, 13(5), 653-676.

Battilana, J., Leca, B., \& Boxenbaum, E. (2009). How actors change institutions: Towards a theory of institutional entrepreneurship. The Academy of Management Annals, 3, 65-107. 
Baum, J.A.C., \& Shipilov, A. (2006). Ecological approaches to organizations. In S. Clegg, C. Hardy, T. Laurence, \& W. North (Eds.), Sage handbook for organization studies (pp. 55-110). London: Sage.

Baum, J.A.C., \& Silverman, B.S. (2001). Complexity, attractors and path dependence and creation in technological evolution. In R. Garud \& P. Karnoe (Eds.), Path as process (pp. 169-209). Hillsdale, NJ: Lawrence Erlbaum Associates.

Beatty, R.P., \& Zajac, E.J. (1994). Managerial incentives, monitoring, and risk bearing: A study of executive compensation, ownership, and board structure in initial public offerings. Administrative Science Quarterly, 39(2), 313-335.

Beckman, C.M., \& Phillips, D.J. (2005). Interorganizational determinants of promotion: Client leadership and the attainment of women attorneys. American Sociological Review, 70(4), 678-701.

Boeker, W. (1988). Organizational origins: Entreprenurial and environmental imprinting at time of founding. In G.R. Carroll (Ed.), Ecological models of organizations (pp. 33-51). Cambridge, MA: Ballinger.

Boeker, W. (1989a). Strategic change: The effects of founding and history. Academy of Management Journal, 32(3), 489-515.

Boeker, W. (1989b). The development and institutionalization of subunit power in organizations. Administrative Science Quarterly, 34(3), 388-410.

Breen, R., \& Jonsson, J.O. (2000). Analyzing educational careers: A multinomial transition model. American Sociological Review, 65(5), 754-772.

Briscoe, F., \& Kellogg, K.C. (2011). The initial assignment effect: Local employer practices and positive career outcomes for work-family program users. American Sociological Review, 76(2), 291-319.

Burt, R.S. (1992). Structural holes: The social structure of competition. Cambridge, MA: Harvard University Press.

Burton, D.M., Sørensen, J.B., \& Beckman, C.M. (2002). Coming from good stock: Career histories and new venture formation. Research in the Sociology of Organizations, 19, 229-262.

Burton, M.D., \& Beckman, C.M. (2007). Leaving a legacy: Position imprints and successor turnover in young firms. American Sociological Review, 72(2), 239-266.

Calori, R., Lubatkin, M., Very, P., \& Veiga, J.F. (1997). Modelling the origins of nationally-bound administrative heritages: A historical institutional analysis of French and British firms. Organization Science, 8(6), 681-696.

Carroll, G.R., \& Hannan, M.T. (1989). Density dependence in the evolution of populations of newspaper organizations. American Sociological Review, 54(4), 524-541.

Carroll, G.R., \& Hannan, M.T. (2004). The demography of corporations and industries. Princeton, NJ: Princeton University Press.

Carroll, G.R., \& Swaminathan, A. (2000). Why the microbrewery movement? Organizational dynamics of resource partitioning in the U.S. brewing industry. The American Journal of Sociology, 106(3), 715-762.

Castilla, E.J. (2008). Gender, race, and meritocracy in organizational careers. American Journal of Sociology, 113(6), 1479-1526.

Chandler, A.D., Jr. (1977). The visible hand: The managerial revolution in American business. Cambridge, MA: Harvard University Press.

Chatterjee, A., \& Hambrick, D.C. (2007). It's all about me: Narcissistic chief executive officers and their effects on company strategy and performance. Administrative Science Quarterly, 52(3), 351-386. 
Chernow, R. (1998). Titan: The life of John D. Rockefeller, Sr. New York: Random House.

Child, J. (1972). Organizational structure, environment and performance: The role of strategic choice. Sociology, 6, 2-21.

Clemens, E.S. (2002). 13. Invention, innovation, proliferation: Explaining organizational genesis and change. In M. Lounsbury \& M.J. Ventresca (Eds.), Social structure and organizations revisited (Research in the sociology of organizations) (Vol. 19, pp. $397-411)$. Amsterdam: JAI.

Cohen, L.E. (2012). Assembling jobs: A model of how tasks are bundled into and across jobs. Organization Science, published online April 3, 2012, doi:10.1287/ orsc. 1110.0737 .

Cooper, D.J., Hinings, B., Greenwood, R., \& Brown, J.L. (1996). Sedimentation and transformation in organizational change: The case of Canadian law firms. Organization Studies, 17(4), 623-647.

Cooper, D.J., Rose, T., Greenwood, R., \& Hinings, B. (2000). History and contingency in international accounting firms. In Y. Aharoni \& L. Nachum (Eds.), Globalization of services: Some implications for theory and practice (pp. 93-124). New York: Routledge.

Dahl, M.S., Dezső, C.L., \& Ross, D.G. (2012). Fatherhood and managerial style: How a male CEO's children affect the wages of his employees. Administrative Science Quarterly, 57(4), 669-693.

David, P.A. (1985). Clio and the economics of QWERTY. The American Economic Review, 75(2), 332-337.

David, P.A. (1994). Why are institutions the "carriers of history"?: Path dependence and the evolution of conventions, organizations and institutions. Structural Change and Economic Dynamics, 5(2), 205-220.

Dew, N., Sarasvathy, S.D., \& Venkataraman, S. (2004). The economic implications of exaptation. Journal of Evolutionary Economics, 14(1), 69-84.

DiMaggio, P.J., \& Powell, W.W. (1983). The iron cage revisited: Institutional isomorphism and collective rationality in organizational fields. American Sociological Review, 48, 147-160.

Dimov, D., de Holan, P.M., \& Milanovy, H. (2012). Learning patterns in venture capital investing in new industries. Industrial and Corporate Change, 21(6), $1389-1426$.

DiPrete, T.A., \& Eirich, G.M. (2006). Cumulative advantage as a mechanism for inequality: A review of theoretical and empirical developments. Annual Review of Sociology, 32(1), 271-297.

DiRenzo, G.J. (1977). Socialization, personality, and social systems. Annual Review of Sociology, 3(1), 261-295.

Djelic, M.-L., \& Ainamo, A. (2005). The telecom industry as cultural industry? The transposition of fashion logics into the field of mobile telephony. In C. Jones \& P.H. Thornton (Eds.), Transformation in cultural industries (Research in the sociology of organizations) (Vol. 23, pp. 45-80). Amsterdam: JAI.

Dobbin, F.R. (1993). The social construction of the great depression: Industrial policy during the 1930s in the United States, Britain, and France. Theory and Society, 22(1), 1-56.

Dobbin, F.R. (1994). Forging industrial policy: The United States, Britain, and France in the railway age. New York: Cambridge University Press. 
Dobrev, S.D., \& Gotsopoulos, A. (2010). Legitimacy vacuum, structural imprinting, and the first mover disadvantage. Academy of Management Journal, 53(5), $1153-1174$.

Dokko, G., Wilk, S.L., \& Rothbard, N.P. (2009). Unpacking prior experience: How career history affects job performance. Organization Science, 20(1), 51-68.

Eisenhardt, K.M., \& Schoonhoven, C.B. (1990). Organizational growth: Linking founding team, strategy, environment, and growth among U.S. semiconductor ventures, 1978-1988. Administrative Science Quarterly, 35(3), 504-529.

Elder, G.H. (1974). Children of the great depression: Social change in life experience. Chicago, IL: University of Chicago Press.

Fallows, J.M. (2012). China airborne (1st ed.). New York: Pantheon Books.

Fan, C.C. (1995). Of belts and ladders: State policy and uneven regional development in post-Mao China. Annals of the Association of American Geographers, 85(3), $421-449$.

Ferriani, S., Garnsey, E., \& Lorenzoni, G. (2012). Continuity and change in a spin-off venture: The process of reimprinting. Industrial and Corporate Change, 21(4), $1011-1048$.

Flanagan, C. (1999). Early socialisation: Sociability and attachment. London: Routledge.

Garud, R., \& Karnøe, P. (2001). Path creation as a process of mindful deviation. In R. Garud \& P. Karnøe (Eds.), Path dependence and creation (pp. 1-40). New York: Lawrence Erlbaum.

Gieryn, T.F. (2000). A space for place in sociology. Annual Review of Sociology, 26(1), $463-496$.

Glynn, M.A., \& Raffaelli, R. (2010). Uncovering mechanisms of theory development in an academic field: Lessons from leadership research. The Academy of Management Annals, 4(1), 359-401.

Gould, S.J. (1980). The Panda's thumb (1st ed.). New York: Norton.

Gould, S.J. (1991). Exaptation: A crucial tool for an evolutionary psychology. Journal of Social Issues, 47(3), 43-65.

Gould, S.J., \& Vrba, E.S. (1982). Exaptation-a missing term in the science of form. Paleobiology, 8(1), 4-15.

Greenwood, R., Díaz, A.M., Li, S.X., \& Lorente, J.C. (2010). The multiplicity of institutional logics and the heterogeneity of organizational responses. Organization Science, 21(2), 521-539.

Greenwood, R., \& Hinings, C.R. (1996). Understanding radical organizational change: Bringing together the old and the new institutionalism. Academy of Management Review, 21(4), 1022-1054.

Greenwood, R., Raynard, M., Kodeih, F., Micelotta, E.R., \& Lounsbury, M. (2011). Institutional complexity and organizational responses. The Academy of Management Annals, 5(1), 317-371.

Greve, H.R., \& Rao, H. (2012). Echoes of the past: Organizational foundings as sources of an institutional legacy of mutualism. American Journal of Sociology, 118(3), $635-675$.

Groysberg, B., Lee, L.-E., \& Nanda, A. (2008). Can they take it with them? The portability of star knowledge workers' performance. Management Science, 54(7), $1213-1230$.

Guillén, M.F. (1994). Models of management: Work, authority, and organization in a comparative perspective. Chicago, IL: University of Chicago Press. 
Gulati, R., \& Westphal, J.D. (1999). Cooperative or controlling? The effects of CEOboard relations and the content of interlocks on the formation of joint ventures. Administrative Science Quarterly, 44(3), 473-506.

Hambrick, D.C. (1989). Guest editor's introduction: Putting top managers back in the strategy picture. Strategic Management Journal, 10(S1), 5-15.

Hannan, M.T., Burton, M.D., \& Baron, J.N. (1996). Inertia and change in the early years: Employment relations in young, high technology firms. Industrial and Corporate Change, 5(2), 503-536.

Hannan, M.T., \& Freeman, J. (1977). The population ecology of organizations. American Journal of Sociology, 82(5), 929-964.

Hannan, M.T., \& Freeman, J. (1984). Structural inertia and organizational change. American Sociological Review, 49(2), 149-164.

Hannan, M.T., \& Freeman, J. (1989). Organizational ecology. Cambridge, MA: Harvard University Press.

Harrison, J.R., Torres, D.L., \& Kukalis, S. (1988). The changing of the guard: Turnover and structural change in the top-management positions. Administrative Science Quarterly, 33(2), 211-232.

Haveman, H.A., \& Rao, H. (1997). Structuring a theory of moral sentiments: Institutional and organizational coevolution in the early thrift industry. The American Journal of Sociology, 102(6), 1606-1651.

Haveman, H.A., Rao, H., \& Paruchuri, S. (2007). The winds of change: The progressive movement and the bureaucratization of thrift. American Sociological Review, 72(1), $117-142$.

Heinroth, O. (1911). Beiträge zur Ethologie, namentlich der Ethologie und Psychologie der Anatiden. In H. Schalow (Ed.), Verhandlungen des V. Internationalen Ornithologen-Kongresses in Berlin, 30. Mai bis 4. Juni 1910 (pp. 589-702). Berlin: Deutsche Ornithologische Gesellschaft.

Hess, E.H. (1959). Imprinting. Science, 130(3368), 133-141.

Higgins, M.C. (2005). Career imprints: Creating leaders across an industry (1st ed.). San Francisco, CA: Jossey-Bass.

Hsu, D.H., \& Kenney, M. (2005). Organizing venture capital: The rise and demise of American research \& development corporation, 1946-1973. Industrial \& Corporate Change, 14(4), 579-616.

Ibarra, H. (1999). Provisional selves: Experimenting with image and identity in professional adaptation. Administrative Science Quarterly, 44(4), 764-791.

Immelmann, K. (1975). Ecological significance of imprinting and early learning. Annual Review of Ecology \& Systematics, 6, 15-37.

Inglehart, R., \& Baker, W.E. (2000). Modernization, cultural change and the persistence of traditional values. American Sociological Review, 65(1), 19-51.

Jepperson, R. (1991). Institutions, institutional effects, and institutionalism. In W.W. Powell \& P. DiMaggio (Eds.), The new institutionalism in organizational analysis (pp. 143-163). Chicago, IL: University of Chicago Press.

Johnson, V. (2007). What is organizational imprinting? Cultural entrepreneurship in the founding of the Paris Opera. American Journal of Sociology, 113(1), 97-127.

Johnson, V. (2008). Backstage at the revolution: How the Royal Paris Opera survived the end of the old regime. Chicago, IL: University of Chicago Press.

Jones, G., \& Khanna, T. (2006). Bringing history (back) into international business. Journal of International Business Studies, 37(4), 453-468. 
Joshi, A., Dencker, J.C., Franz, G., \& Martocchio, J.J. (2010). Unpacking generational identities in organizations. Academy of Management Review, 35(3), 392-414.

Kacperczyk, A. (2009). Inside or outside: The social mechanisms of entrepreneurships choices. Evidence from the mutual fund industry. Ann Arbor, MI: University of Michigan.

Kalev, A., Dobbin, F., \& Kelly, E. (2006). Best practices or best guesses? Assessing the efficacy of corporate affirmative action and diversity policies. American Sociological Review, 71, 589-617.

Kieser, A. (1994). Why organization theory needs historical analyses-and how this should be performed. Organization Science, 5(4), 608-620.

Kimberly, J.R. (1975). Environmental constraints and organizational structure: A comparative analysis of rehabilitation organizations. Administrative Science Quarterly, 20, $1-9$.

Kimberly, J.R. (1979). Issues in the creation of organizations: Initiation, innovation, and institutionalization. The Academy of Management Journal, 22(3), 437-457.

Kimberly, J.R., \& Bouchikhi, H. (1995). The dynamics of organizational development and change: How the past shapes the present and constrains the future. Organization Science, 6(1), 9-18.

Kogut, B. (1993). Learning, or the importance of being inert: Country imprinting and international competition. In S. Ghoshal \& E. Westney (Eds.), Organization theory and the multinational corporation (pp. 136-154). New York: St Martin's Press.

Kogut, B., \& Zander, U. (2000). Did socialism fail to innovate? A natural experiment of the two Zeiss companies. American Sociological Review, 65(2), 169-190.

Kriauciunas, A., \& Kale, P. (2006). The impact of socialist imprinting and search on resource change: A study of firms in Lithuania. Strategic Management Journal, $27(7), 659-679$.

Leblebici, H., Salancik, G.R., Copay, A., \& King, T. (1991). Institutional change and the transformation of interorganizational history of the U.S. radio broadcasting industry. Administrative Science Quarterly, 36(3), 333-363.

Lin, L.-W. (2010). Corporate social responsibility in China: Window dressing or structural change? Berkeley Journal of International Law, 28(1), 64-100.

Lorenz, K. (1935). Der Kumpan in der Umwelt des Vogels. Der Artgenosse als auslösendes Moment sozialer Verhaltensweisen. Journal für Ornithologie, 83, 137-413.

Lorenz, K. (1937). On the formation of the concept of instinct. Natural Sciences, 25(19), $289-300$.

Lounsbury, M. (2002). Institutional transformation and status mobility: The professionalization of the field of finance. Academy of Management Journal, 45, 255-266.

Lounsbury, M. (2007). A tale of two cities: Competing logics and practice variation in the professionalizing of mutual funds. Academy of Management Journal, 50(2), $289-307$.

Lounsbury, M., \& Ventresca, M. (2002). Social structures and organizations revisited. In M. Lounsbury \& M. Ventresca (Eds.), Research in the sociology of organizations (Vol. 19, pp. 3-26). New York: JAI/Elsevier.

Mahoney, J. (2000). Path dependence in historical sociology. Theory and Society, 29(4), $507-548$.

Malmendier, U., \& Nagel, S. (2011). Depression babies: Do macroeconomic experiences affect risk taking? The Quarterly Journal of Economics, 126(1), 373-416. 
Marquis, C. (2003). The pressure of the past: Network imprinting in intercorporate communities. Administrative Science Quarterly, 48, 655-689.

Marquis, C., \& Battilana, J. (2009). Acting globally but thinking locally? The influence of local communities on organizations. Research in Organizational Behavior, 29, $283-302$.

Marquis, C., Davis, G.F., \& Glynn, M.A. (2013). Golfing alone? Corporations, elites and nonprofit growth in 100 American communities. Organization Science, 24(1), $39-57$.

Marquis, C., \& Huang, Z. (2010). Acquisitions as exaptation: The legacy of founding institutions in the U.S. commercial banking industry. Academy of Management Journal, 53(6), 1441-1473.

Marquis, C., \& Qian, C. (2013). Corporate social responsibility reporting in China: Symbol or substance? Organization Science (forthcoming).

Mayo, A.J., \& Nohria, N. (2005). In their time: The greatest business leaders of the twentieth century. Boston, MA: Harvard Business School Press.

McEvily, B., Jaffee, J., \& Tortoriello, M. (2012). Not all bridging ties are equal: Network imprinting and firm growth in the Nashville legal industry, 1933-1978. Organization Science, 23(2), 547-563.

Meyer, J.W., \& Rowan, B. (1977). Institutionalized organizations: Formal structure as myth and ceremony. The American Journal of Sociology, 83(2), 340-363.

Meyer, M.W., \& Brown, M.C. (1977). The process of bureaucratization. American Journal of Sociology, 83(2), 364-385.

Miles, W.E., Snow, C.C., \& Pfeffer, J. (1974). Organization-environment: Concepts and issues. Industrial Relations, 13(3), 244-264.

Miner, A.S. (1991). Organizational evolution and the social ecology of jobs. American Sociological Review, 56(6), $772-785$.

Mizruchi, M.S., \& Stearns, L.B. (2001). Getting deals done: The use of social networks in bank decision-making. American Sociological Review, 66, 647-671.

Nasaw, D. (2006). Andrew Carnegie. New York: Penguin Press.

North, D.C. (1990). Institutions, institutional change, and economic performance. Cambridge: Cambridge University Press.

O'Mahony, S., \& Ferraro, F. (2007). The emergence of governance in an open source community. Academy of Management Journal, 50(5), 1079-1106.

O'Mahony, S., \& Lakhani, K.R. (2011). Organizations in the shadow of communities. In C. Marquis, M. Lounsbury, \& R. Greenwood (Eds.), Communities and organizations (Research in the sociology of organizations) (Vol. 33, pp. 3-36). Bingley: Emerald Group.

Pache, A.-C., \& Santos, F. (2010). When worlds collide: The internal dynamics of organizational responses to conflicting institutional demands. Academy of Management Review, 35(3), 455-476.

Page, S.E. (2006). Path dependence. Quarterly Journal of Political Science, 1(1), $87-115$.

Palmer, D., \& Barber, B.M. (2001). Challengers, elites, and owning families: A social class theory of corporate acquisitions in the 1960s. Administrative Science Quarterly, 46(1), 87-120.

Peng, Y. (2004). Kinship networks and entrepreneurs in China's transitional economy. American Journal of Sociology, 109(5), 1045-1074. 
Pennings, J.M. (1980). Environmental influences on the creation process. In J.R. Kimberly \& R.H. Miles (Eds.), The organizational life cycle (pp. 134-160). San Francisco, CA: Jossey-Bass.

Perrow, C. (1984). Normal accidents: Living with high-risk technologies. New York: Basic Books.

Perrow, C. (1999). Organizing to reduce the vulnerabilities of complexity. Journal of Contingencies \& Crisis Management, 7(3), 150-155.

Pfeffer, J., \& Salancik, G.R. (1978). The external control of organizations: A resource dependence perspective. New York: Harper \& Row.

Phillips, D.J. (2005). Organizational genealogies and the persistence of gender inequality: The case of Silicon Valley law firms. Administrative Science Quarterly, 50(3), $440-472$.

Portes, A. (1998). Social capital: Its origins and applications in modern sociology. Annual Review of Sociology, 24, 1-24.

Powell, W.W. (1991). Expanding the scope of institutional analysis. In W.W. Powell \& P. DiMaggio (Eds.), The new institutionalism in organizational analysis (pp. 183-203). Chicago, IL: University of Chicago Press.

Rao, H., Monin, P., \& Durand, R. (2003). Institutional change in Toque ville: Nouvelle cuisine as an identity movement in French gastronomy. American Journal of Sociology, 108(4), 795-843.

Raynard, M., Lounsbury, M., \& Greenwood, R. (2013). Legacies of logics: Sources of community variation in CSR implementation in China. In M. Lounsbury \& E. Boxenbaum (Eds.), Research in the sociology of organizations: Institutional logics in action (pp. forthcoming). Bingley: Emerald Group.

Rosenbaum, J.E. (1979). Tournament mobility: Career patterns in a corporation. Administrative Science Quarterly, 24(2), 220-241.

Rosenkopf, L., \& Almeida, P. (2003). Overcoming local search through alliances and mobility. Management Science, 49(6), 751-766.

Rosow, I. (1978). What is a cohort and why? Human Development, 21, 65-75.

Ruef, M. (2002). 6. Unpacking the liability of aging: Toward a socially-embedded account of organizational disbanding. In M. Lounsbury \& M.J. Ventresca (Eds.), Social structure and organizations revisited (research in the sociology of organizations) (Vol. 19, pp. 195-228). Amsterdam: JAI.

Ryder, N.B. (1965). The cohort as a concept in the study of social change. American Sociological Review, 30(6), 843-861.

Schein, E.H. (1971). The individual, the organization, and the career: A conceptual scheme. The Journal of Applied Behavioral Science, 7(4), 401-426.

Schneiberg, M. (2002). Organizational heterogeneity and the production of new forms: Politics, social movements and mutual companies in American fire insurance, 1900 - 1930. In M. Lounsbury \& M. Ventresca (Eds.), Research in the sociology of organizations (Vol. 19, pp. 39-89). Amsterdam: JAI.

Schoar, A., \& Zuo, L. (2011). Shaped by booms and busts: How the economy impacts CEO careers and management style (Working Paper). National Bureau of Economic Research.

Scott, W.R. (2008). Institutions and organizations: Ideas and interests (3rd ed.). Los Angeles, CA: Sage.

Selznick, P. (1957). Leadership in administration: A sociological interpretation. New York: Harper \& Row. 
Shinkle, G.A., \& Kriauciunas, A.P. (2012). The impact of current and founding institutions on strength of competitive aspirations in transition economies. Strategic Management Journal, 33(4), 448-458.

Soda, G., Usai, A., \& Zaheer, A. (2004). Network memory: The influence of past and current networks on performance. The Academy of Management Journal, 47(6), $893-906$.

Sørensen, J.B. (2004). The organizational demography of racial employment segregation. American Journal of Sociology, 110(3), 626-671.

Spalding, D.A. (1873 [1902]). Instinct. With original observations on young animals. Popular Science Monthly, June, 126-142.

Stinchcombe, A.L. (1965). Social structure and organizations. In J.G. March (Ed.), Handbook of organizations (pp. 142-193). Chicago, IL: Rand McNally.

Sullivan, B.N., Tang, Y., \& Marquis, C. (2013). Persistently learning: How small-world network imprints and organizational adaptation affect firm performance (Working Paper). Boston, MA: Harvard Business School.

Swaminathan, A. (1996). Environmental conditions at founding and organizational mortality: A trial-by-fire model. Academy of Management Journal, 39, $1350-1377$.

Sydow, J., Schreyögg, G., \& Koch, J. (2009). Organizational path dependence: Opening the black box. Academy of Management Review, 34(4), 689-709.

Tilcsik, A. (2010). From ritual to reality: Demography, ideology, and decoupling in a post-communist government agency. The Academy of Management Journal, 53(6), $1474-1498$.

Tilcsik, A. (2012). Remembrance of things past: Individual imprinting in organizations. Cambridge, MA: Harvard University.

Tucker, D.J., Singh, J.V., \& Meinhard, A.G. (1990). Founding characteristics, imprinting and organizational change. In J.V. Singh (Ed.), Organizational evolution: New directions (pp. 182-200). Newbury Park, CA: Sage.

Tushman, M.L., \& Romanelli, E. (1985). Organizational evolution: A metamorphosis model of convergence and reorientation. In L.L. Cummings \& B.M. Staw (Eds.), Research in organizational behavior (Vol. 7, pp. 171-222). Greenwich, CT: JAI Press.

Üsdiken, B., \& Kieser, A. (2004). Introduction: History in organisation studies. Business History, 46(3), 321-330.

Van Maanen, J., \& Schein, E.H. (1979). Toward a theory of organizational socialization. Research in organizational behavior, 1(1), 209-264.

Vergne, J.-P., \& Durand, R. (2010). The missing link between the theory and empirics of path dependence: Conceptual clarification, testability issue, and methodological implications. Journal of Management Studies, 47(4), 736-759.

Walsh, J.P. (1988). Top management turnover following mergers and acquisitions. Strategic Management Journal, 9(2), 173-183.

Westphal, J.D., \& Zajac, E.J. (2001). Decoupling policy from practice: The case of stock repurchase programs. Administrative Science Quarterly, 46(2), 202-228.

Xiao, Z., \& Tsui, A.S. (2007). When brokers may not work: The cultural contingency of social capital in Chinese high-tech firms. Administrative Science Quarterly, 52(1), $1-31$. 
Zald, M.N. (1990). History, sociology, and theories of organization. In J.E. Jackson (Ed.), Institutions in American society (pp. 81-108). Ann Arbor, MI: University of Michigan Press.

Zaring, O., \& Eriksson, C.M. (2009). The dynamics of rapid industrial growth: Evidence from Sweden's information technology industry, 1990-2004. Industrial \& Corporate Change, 18(3), 507-528.

Zyglidopoulos, S. (1999). Initial environmental conditions and technological change. Journal of Management Studies, 36(2), 241-262. 